TI 2014-033/II

Tinbergen Institute Discussion Paper

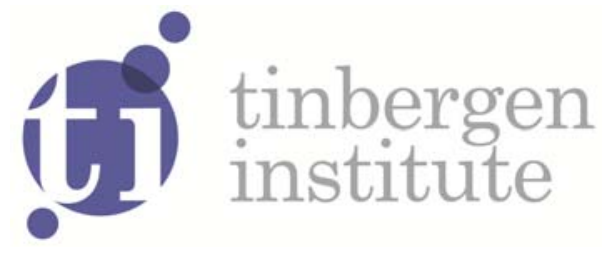

\title{
The Great Divergence: A Network Approach
}

\author{
Ines Lindner' \\ Holger Strulik²
}

1 Faculty of Economics and Business Administration, VU University Amsterdam, and Tinbergen Institute, the Netherlands;

2 Georg-August-Universität Göttingen, Germany. 
Tinbergen Institute is the graduate school and research institute in economics of Erasmus University Rotterdam, the University of Amsterdam and VU University Amsterdam.

More TI discussion papers can be downloaded at http://www.tinbergen.nl

Tinbergen Institute has two locations:

Tinbergen Institute Amsterdam

Gustav Mahlerplein 117

1082 MS Amsterdam

The Netherlands

Tel.: +31(0)205251600

Tinbergen Institute Rotterdam

Burg. Oudlaan 50

3062 PA Rotterdam

The Netherlands

Tel.: +31(0)10 4088900

Fax: $+31(0) 104089031$

Duisenberg school of finance is a collaboration of the Dutch financial sector and universities, with the ambition to support innovative research and offer top quality academic education in core areas of finance.

DSF research papers can be downloaded at: http://www.dsf.nl/

Duisenberg school of finance

Gustav Mahlerplein 117

1082 MS Amsterdam

The Netherlands

Tel.: +31(0)20 5258579 


\title{
The Great Divergence: A Network Approach *
}

\author{
Ines Lindner ${ }^{\dagger}$ and Holger Strulik**
}

First Draft: March 2014.

\begin{abstract}
We present a multi-country theory of economic growth in which countries are connected by a network of mutual knowledge exchange. Growth is generated through human capital accumulation and knowledge externalities. The available knowledge in any country depends on its connections to the rest of the world and on the human capital of the countries it is exchanging knowledge with. We show how the diffusion of knowledge through the world explains the evolution of global income inequality. It generates a "Great Divergence", that is increasing world inequality after the take-off of the forerunners of the industrial revolution, followed by a "Great Convergence", that is decreasing world inequality after the take-off of the latecomers of the industrial revolution. Knowledge diffusion through a Small World network produces an extraordinary diversity of individual growth experiences of initially identical countries including differentiated take-offs to growth as well as overtaking and falling behind in the course of world development.
\end{abstract}

Keywords: networks, knowledge diffusion, economic growth, world income distribution. JEL: O10; O40; D62; D85; F41.

\footnotetext{
${ }^{*}$ We would like to thank Jean-Louis Arcand, Franois Bourguignon, Clive Bell, Christiane Clemens, Oded Galor, Jan Willem Gunning, Guido Cozzi, Alessandra Pelloni, Robert Waldmann, and David Weil for helpful comments. †Tinbergen Institute and VU University Amsterdam, Department of Econometrics and Operations Research, De Boelelaan 1105, 1081 HV Amsterdam, The Netherlands, email: ilindner@feweb.vu.nl

**University of Göttingen, Department of Economics, Platz der Göttinger Sieben 3, 37073 Göttingen, Germany; email: holger.strulik@wiwi.uni-goettingen.de.
} 


\section{INTRODUCTION}

In pre-modern times, before the take-off to long-run growth of the leader countries of the industrial revolution, national income differences were minuscule from today's perspective. Bairoch (1993, Ch. 9) reviews the literature and comes to the conclusion that even in the mid 18th century the differential between the future least developed countries and the future developed countries was of the order of 1 to $1.1-1.3$. From then on, the world witnessed the Great Divergence (Pommeranz, 2000). Income inequality between countries, measured by the Theil index, increased from 0.06 in 1820 to 0.25 in 1870 to 0.48 in 1950 to 0.5 in 1980 (according to Bourguignon and Morrisson, 2002). Since then the increase of inequality slowed down such that researchers speculate whether it has settled at a steady state or started to decline (e.g. Jones, 1997; Acemoglu and Ventura, 2002, Sutcliffe, 2002). Figure 1 shows the gradual increase of world income growth and the evolution of world inequality since the onset of the industrial revolution. ${ }^{1}$

Figure 1: World Economic Growth and Inequality
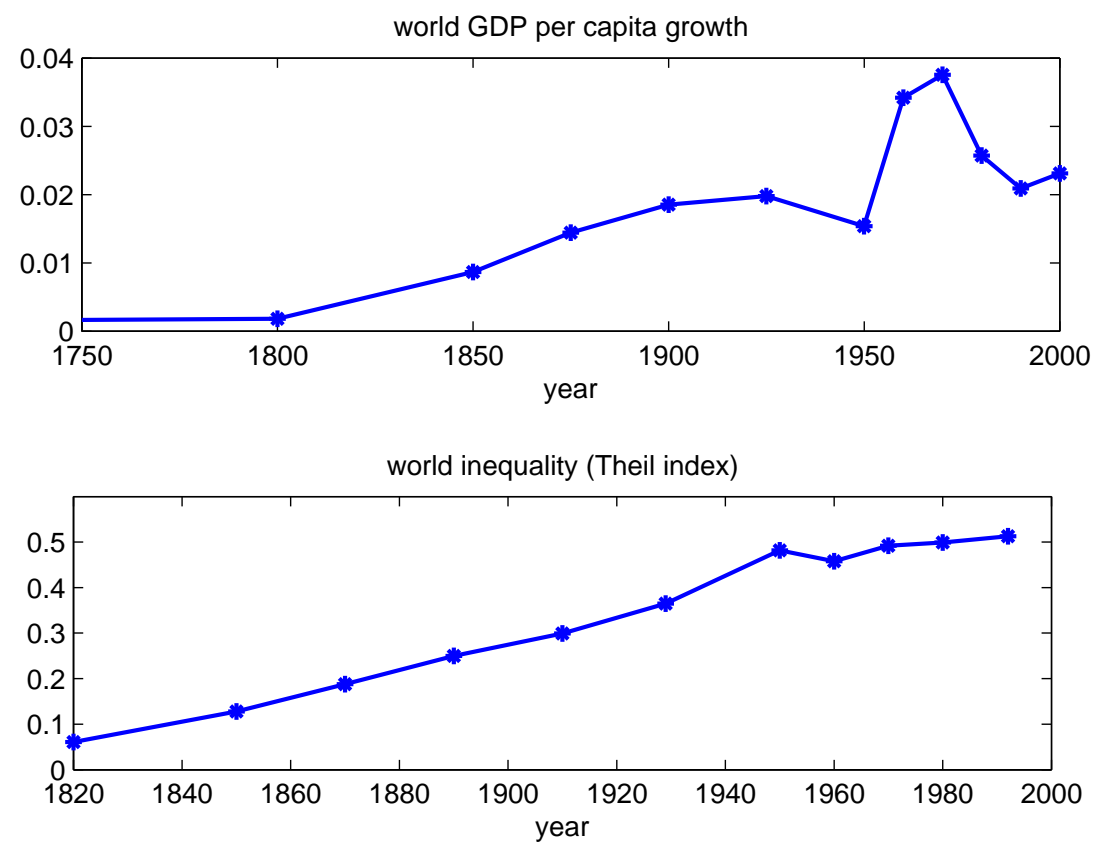

Data from De Long (1998) and Bouguignon and Morrisson (2002).

The country-specific differences in the timing of the gradual take off from stagnation to longrun growth are a major theme in unified growth theory (Galor, 2005, 2011). It is argued that the

\footnotetext{
${ }^{1}$ We refer to the inequality of GDP per capita between countries, which is the relevant measure for the theory developed below. For inequality of income between world citizens the evidence is stronger that it actually declined since the 1980s due to the take-off of populous China and India (Sala-i-Martin, 2006).
} 
varying time of the take-off to growth contributed significantly to increasing world inequality and the emergence of convergence clubs (i.e. clusters of countries that grow similarly with respect to each other but differently to other countries). Unified growth theory, however, largely focusses on countries conceptualized as closed economies, which implies, in particular, the notion that each country generated independently its own impulse for the take-off to growth. ${ }^{2}$

The present paper proposes a different approach. It considers a world of many countries connected by a network of knowledge exchange. As knowledge diffuses gradually through the world, more and more countries are "infected", their population starts investing into education, and their economy takes off to long-run growth. With more and more countries jumping on the bandwagon of growth, world income per capita increases gradually towards a balanced growth path. The individual timing of the take off is explained by the countries' closeness to the leaders of the industrial revolution. Countries which are connected directly, or with only a few links, adopt the knowledge created in the leader countries earlier than poorly connected or "remote" countries. Take off to growth of the forerunners of the industrial revolution is, naturally, accompanied by increasing world inequality, as the income gap with respect to the backward countries gets larger. Eventually, however, knowledge diffuses through the whole world and also the remote countries take off. Because the available knowledge has increased tremendously since the take off of the original leaders, the latecomers of the industrial revolution have more to learn from and thus they take off faster, at rates that temporarily exceed the balanced growth rate. The feature that growth rates of latecomers overshoot implies that world inequality eventually declines.

In order to focus on the knowledge diffusion process, the underlying economic model is a deliberately simple one. It is basically a multi-country version of Romer (1986). The main difference is that a country's factor productivity does not only depend on the human capital of its own workforce but also on the human capital of the countries with which it is connected. Figuratively speaking, countries need not to re-invent the wheel or the steam engine. Backward countries benefit from knowledge exchange with the technological leaders. Together with a network for knowledge exchange this provides a minimum setup in order to explain how a

\footnotetext{
${ }^{2}$ See Galor and Weil (2000), Kögel and Prskawetz (2001), Jones, 2001, Galor and Moav (2002, 2004), Boucekkine et al. (2002), Doepke (2004), Strulik and Weisdorf (2008), and many others. The study by Galor and Mountford (2008) is an exception in that it considers two interacting countries (or regions). It investigates trade - but not knowledge exchange - and argues that the fact that countries are connected delays the take off to growth of the initially backward country.
} 
diversity of individual growth experiences evolves out of initial similarity between countries. In contrast to conventional unified growth theory, the model is too simple to explain the transition of the leader countries out of stagnation. Here we just give the leader countries a small head start that allows them to grow initially. We think that this approach is justifiable because of our focus on the differentiated take offs and growth experiences across countries that happened after the take off of the leader countries.

Our study was inspired by the work of Lucas $(2000,2009)$. Like us Lucas investigates initial divergence and subsequent convergence of income across countries in a multi-country version of a simple economic model. In the 2000 paper growth is exogenous and in the 2009 paper growth is, as in our study, driven by human capital accumulation and access to human capital of others. An important difference is that in Lucas' studies countries have either full access or no access to world knowledge. There is no network of knowledge exchange and no evolving diversity of individual growth experiences. A stochastic mechanism determines when countries get access to world knowledge. According to our approach, in contrast, the economic take off and subsequent growth of the leaders, followers and trailers of industrial revolution is endogenously explained and understood by the increasing diffusion of knowledge through the world. Growth of the leading country (the knowledge frontier) is exogenous in Lucas' world whereas in our model all growth is endogenous. This allows us to explain a richer set of phenomena. For example, according to Lucas' approach, the US would never had outpaced England, the erstwhile industrial leader. In our setup, countries do not only temporarily diverge and converge but they are also (occasionally) overtaking each other. We also demonstrate that the network architecture itself has an impact on the success of industrialization and that, in this sense, the industrial revolution was not inevitable.

There exists also a relatively large literature on R\&D spillovers between countries (e.g. Eaton and Kortum, 1999; Howitt, 2000). This literature involves usually a rather sophisticated modeling of households and firms but the way knowledge is exchanged between countries is straightforward and (most of) the analysis concerns the steady state. In the present paper the economic model is straightforward but the process of knowledge diffusion is non-trivial and the analysis fo- 
cusses on transitional dynamics. ${ }^{3}$ Another strand of literature investigates multi-country models in which convergence is driven by capital accumulation and trade (e.g. Acemoglu and Ventura, 2002). Conceptually, the available multi-country growth literature focusses on the question whether and how initially different countries converge while we also investigate how initially similar countries diverged. In other words we share with the available multi-country growth literature an interest in the question where the steady-state cross-country income distribution is but we also share with unified growth theory an interest in the question how the presently observable diversity of growth experiences evolved out of initial similarity between countries. In a unifying framework our network theory of knowledge diffusion offers an explanation for both "the great divergence" as well as "the great convergence".

There exists a small literature on networks in the context of economic growth. Most closely related is perhaps the study by Cavalcanti and Giannitsarou (2012) who investigate learning externalities between households (or schools) in simple networks and focus on convergence behavior. Fogli and Veldkamp (2012) provide a study on the role of network connectivity for the diffusion of knowledge and diseases. Lindner and Strulik (2013) investigate how economic development is affected by globalization conceptualized as an evolving network, i.e. how decreasing local connectivity affects occupational choice and investment behavior through eroding trust and trustworthiness.

According to Jones and Romer (2010) the "old" stylized facts of growth, set up by Kaldor (1961), are now largely explained by neoclassical theory. Meanwhile, they argue, results from contemporary growth empirics established "new Kaldor facts" as guideline and challenge for future developments in the theory of economic growth. We think, that our theory addresses five of these six new facts: 1) increasing flow of ideas through globalization, 2) accelerating growth rates, 3) cross-country variation of growth rates that increases with distance from the technology frontier, 4) large income and TFP differences across countries, 5) increases in human capital per worker throughout the world. ${ }^{4}$ Since the underlying Romer (1986) model is - as a stand-alone unit - too simple to allow for an explanation of (most of) the new facts, we conclude a non-

\footnotetext{
${ }^{3}$ Klenow and Rogriguez-Clare (2005) survey the literature on knowledge externalities in economic growth and propose some extensions. In particular, they consider to let knowledge diffusion to be country-pair specific and depending on distance (but they do not pursue this approach very far, cf. pp. 852-3). Recently Comin et al. (2012) developed a micro-founded theory of spacial knowledge diffusion based on random interaction of individuals. Their paper is also indirectly supportive of our approach by showing empirically that knowledge diffuses slower to countries farther away from the technological leaders.

${ }^{4}$ We cannot address Jones and Romer's (2010) sixth fact concerning the stable skill premium because countries are, for simplicity, assumed to be populated by representative households.
} 
negligible value added from the consideration of networks in the theory of economic growth.

The paper is organized as follows. The next section introduces the basic model. In Section 3 we provide analytical results for comparative statics and comparative dynamics (steady-state, s-shaped transitions, overshooting growth of latecomers, rising and eventually declining world inequality). Proofs of the propositions are delegated to the Appendix. In Section 4 we investigate the implied growth dynamics for some very simple networks in order to provide a better understanding of the impact of the network architecture on knowledge diffusion. In Section 5 we introduce the Small World network (Watts and Strogatz, 1998) and investigate the distribution and growth of world income when countries are connected by such a network. We argue that the Small World network is already sufficiently complex to generate growth trajectories consistent with the new Kaldor facts. We provide a sensitivity analysis with respect to network parameters and initial conditions and discuss the possibility and inevitability of an industrial revolution. Section 6 concludes.

\section{The Model}

2.1. Households and Firms. Consider a world consisting of a number $n$ of countries indexed by $i$. Countries share the same economic structure but differ potentially in their endowments and their connections to other countries. Each country is inhabited by two overlapping generations of measure one. A household consists of one adult and one child. The representative adult born at time $t-1$ in country $i$ maximizes utility experienced from consumption above subsistence needs $c_{i t}$ and from the future income of his or her child $y_{i, t+1}$. Assuming, for simplicity, a log form of the utility function the objective is to maximize

$$
u_{i t}=\log c_{i t}+\beta \log y_{i, t+1}
$$

for $y_{i t}>\bar{c}$. The parameter $\beta$ denotes the weight of future income in utility. The household budget constraint is given by

$$
y_{i t}=\bar{c}+c_{i t}+e_{i t},
$$

in which $\bar{c}$ are subsistence needs and $e_{i t}$ is expenditure for child education. Moreover, we require $c_{i t}, e_{i t} \geq 0$ and set $c_{i t}=y_{i t}$ and $u_{i t}=-\infty$ for $y_{i t} \leq \bar{c}$. The existence of subsistence needs

motivates in a straightforward way the fact that investment in education increases gradually with increasing family income. Education translates into human capital via a simple iso-elastic 
production function,

$$
h_{i, t+1}=\max \left\{1, B e_{i t}^{\eta}\right\}
$$

The assumption that the next generation has at least one unit of human capital (innate skills) ensures long-run survival of mankind. It implies that the equation of motion exhibits a kink at unity. Such a kink could be motivated by assuming that $h_{i t}=1$ is associated with the skills to perform subsistence farming, i.e. skills which are obtained without cost by observing the parents working on the fields and which become obsolete when the individual gets an education and an occupation outside subsistence farming. The assumption allows to capture in a straightforward way the fact that all countries experienced a history in which mass education was not worthwhile. We assume $0<\eta \leq 1$ but focus mainly on the case where $\eta=1$ because it allows for positive growth at the steady-state. Our description of human capital accumulation is admittedly very stylized compared with its sophisticated modeling in unified growth theory (Galor and Weil, 2000, Galor, 2005) but it captures the same stylized facts: mass education becomes only worthwhile when technology has advanced sufficiently far and it then gradually increases with economic development. We introduce this "shortcut" modeling of intergenerational decision making because we want to focus on the phenomenon of knowledge diffusion around the world.

Every country is populated by a large number of competitive firms. The representative firm of country $i$ at time $t$ produces per capita output (GDP)

$$
y_{i t}=A_{i t} h_{i t}^{\alpha}
$$

Factor productivity $A_{i t}$ is given for the single firm but endogenously determined through knowledge externalities from other firms. Because there are no other private inputs in production aside from human capital, the representative household earns income $y_{i t}$. Inserting (2)-(4) into (1) and solving the problem provides education effort

$$
e_{i t}= \begin{cases}\frac{\alpha \beta \eta}{1+\alpha \beta \eta} \cdot\left(y_{i t}-\bar{c}\right) & \text { for } \frac{\alpha \beta \eta}{1+\alpha \beta \eta} \cdot\left(y_{i t}-\bar{c}\right)>(1 / B)^{1 / \eta} \\ 0 & \text { otherwise. }\end{cases}
$$

Education effort is increasing in household income except for poor households, close to subsistence, who cannot afford education. For perpetually growing income, the income share spent on education converges towards a constant. 
Inserting income (4) and education (5) into (3) we obtain the (gross) growth rate of human capital.

$$
g_{i t}^{h} \equiv \frac{h_{i, t+1}}{h_{i t}}=\max \left\{\frac{1}{h_{i t}}, L \cdot \frac{\left(A_{i t} h_{i t}^{\alpha}-\bar{c}\right)^{\eta}}{h_{i t}}\right\}, \quad L \equiv B\left(\frac{\alpha \beta \eta}{1+\alpha \beta \eta}\right)^{\eta}
$$

2.2. Knowledge Externalities. Following Arrow (1962) and Romer (1986) we assume that firm productivity is given by the knowledge that can be absorbed from knowledge created via production elsewhere. In contrast to Arrow and Romer we assume that firms have access to the knowledge created in other countries (for example through the flow of goods and people). A link between two countries $i$ and $j$ thus means that these countries are open with respect to each other and that they are in mutual knowledge exchange.

The world network of knowledge exchange is represented by a matrix $\mathbf{W}$ whose elements indicate whether countries are linked with each other. For simplicity we assume that links are unweighted and undirected. This means that the entry $w_{i j}=w_{j i}$ is equal to one if countries $i$ and $j$ are linked and zero otherwise. The nodes to which country $i$ is linked are called neighbors of $i$. Assume country $i$ has $d_{i}$ links. By definition, each country is not linked to itself such that $d_{i}$ can assume any value between 0 (isolation) and $n-1$ (connected to all other countries). Let $N_{i}$ denote the neighborhood of $i$, i.e. the set of countries to which country $i$ is linked.

Let $\epsilon$ denote the share of international knowledge spillovers, $\epsilon \in[0,1]$. Knowledge spillovers from abroad are derived from the externality matrix $\mathbf{\mathbf { W }}$, which is obtained by normalizing $\mathbf{W}$ such that for every linked country, $d_{i}>0$, the sum of weights to neighbors in $\overline{\mathbf{W}}$ is equal to $\epsilon$, that is $\bar{w}_{i j}=\epsilon / d_{i}$ for $j \in N_{i}$. In case of isolation $d_{i}=0$ and we set $\bar{w}_{i j}=0$ for all $j \neq i$. Finally, we assign $\bar{w}_{i i}=1-\epsilon$ for all $i$. Hence all rows of $\overline{\mathbf{W}}$ have positive elements and sum up to one if every country has at least one link.

We define the knowledge externality for country $i$ as the average human capital input in production of all neighbors, including the country itself.

$$
A_{i t}=\left(\sum_{j=1}^{n} \bar{w}_{i j} h_{j t}\right)^{1-\alpha}=\left(\epsilon \bar{h}_{i t}+(1-\epsilon) h_{i t}\right)^{1-\alpha}
$$

in which the average human capital of the neighbors of $i$ is denoted by $\bar{h}_{i t}=\frac{1}{d_{i}} \sum_{j \in N_{i}} h_{j t}$. For $\epsilon=0$ the model collapses to the Romer (1986) model, in which countries are treated as if in 
isolation. $^{5}$

The intuition behind the use of country averages is that at any time increment any person in country $i$ can exchange knowledge either with a person in country $j$ or country $k$. The fact that aggregate time for knowledge exchange per country is normalized to unity then implies that the total knowledge acquired is given by the average of the human capital of its neighbors. Ceteris paribus, a link to a backward country (with $h_{j t}<h_{i t}$ ) leads to a lower knowledge externality for country $i$ and a link to a forward country (with $h_{j t}>h_{i t}$ ) implies a higher knowledge externality. This means that initially backward countries that are well connected to initially rich countries have an advantage in learning from abroad whereas initially rich countries that are mainly connected with poor countries experience a drawback in knowledge accumulation because there is relatively little to be learned from abroad.

\section{Long Run Dynamics}

From (6) and (7) we get a description of the world as one vector-valued difference equation,

$$
h_{i t+1}=\max \left\{1, L \cdot\left(\left[\epsilon \bar{h}_{i t}+(1-\epsilon) h_{i t}\right]^{1-\alpha} h_{i t}^{\alpha}-\bar{c}\right)^{\eta}\right\}
$$

$i=1, \ldots, n$, and a network $\mathbf{\mathbf { W }}$. Note that in case of isolation, $\bar{h}_{i t}=0$ which is always harmful to growth.

Let $H_{t} \equiv \sum_{i=1}^{n} h_{i t}$ and $\bar{h}_{t} \equiv H_{t} / n$ denote the world-wide stock of human capital and the average human capital endowment per person, respectively. Furthermore, let $g_{t}^{h} \equiv H_{t+1} / H_{t}$ denote the growth rate of world human capital and $x_{i t}=h_{i t} / \bar{h}_{t}$ country $i$ 's relative endowment, i.e. the ratio between country $i$ 's human capital and average human capital. Whether economies are able to have positive growth in the long run is determined by $\eta$ and $L$.

Proposition 1. There is no long run growth, i.e. $\lim _{t \rightarrow \infty} g_{i t}^{h}=0$ for all $i=1, \ldots n$, for $\eta<1$ and for $\eta=1$ if $L \leq 1$.

Definition 1. A Steady State is defined by each country growing at the same constant growth rate, i.e. $g_{i t}=g$ such the relative human capital stays the same for each country, i.e. $x_{i t+1}=x_{i}$.

${ }^{5}$ In the Appendix we discuss also the case of $A_{i t}=\left(\sum_{j=1}^{n} \bar{w}_{i j} h_{j t}\right)^{\omega}, \omega<1-\alpha$. In this case knowledge externalities are too weak for positive growth to be sustainable at the steady-state. Nevertheless the calibrated model can produce plausible adjustment dynamics vis a vis the historical trends. In this sense the "knife-edge" assumption $\omega=1-\alpha$ is not crucial for our main results. 
Proposition 2. When all countries start with equal initial human capital $h_{0}$ and there are no isolated countries, the network is irrelevant and the economy is always at the steady-state where $x_{i t+1}=x_{i}=1$ for all $i \in N$ and $t=1,2, \ldots$.

This means that the Romer (1986) model is included as a special case when the world consists of identical countries. The next proposition rules out unequal equilibria for $\eta<1$ if the network is connected. A network is connected if there exists a path between any two nodes. Formally, for any $i$ and $j, i \neq j$, there exists a $k \geq 1$ such that $\left(\overline{\mathbf{W}}^{k}\right)_{i j}>0$.

Proposition 3. Consider the world as a connected network $\overline{\mathbf{W}}$. For $\eta<1$, human capital and income of all countries eventually converge to the same level. There are at most two different steady states above subsistence level. If $\eta=1$ and $L \leq 1$, the world eventually converges to subsistence level $\bar{c}$.

So far results have just confirmed for the multi-country world what we already know from the closed country Romer model. From now on, however, results deviate.

Proposition 4 (Long-Run Growth). For $\eta=1$ and $L>1$ the economy has the potential for positive long-run growth at rate $g^{*}=L$. If the network $\overline{\mathbf{W}}$ is connected the world economy converges towards a steady-state (of growth or stagnation).

Notice the difference to Romer (1986). There, $L>1$ and linear factor accumulation, i.e. $\eta=1$ (in our notation), inevitably produce long-run growth. Here, these conditions make longrun growth feasible. In fact, if the network architecture is unfavorable, long-run growth will not occur. We elaborate on this phenomenon in Section 5.2. If the network is connected, all knowledge is eventually shared by all countries. This feature implies that the world economy converges towards a steady-state, i.e. a situation in which all countries grow at a common rate. A steady-state of positive growth means that all countries of the world irrespective of their backward initial situation are eventually "infected" by knowledge diffusion and will grow eventually at the same rate as the leaders of the industrial revolution.

The shape of the path of a country's economic development is crucially determined by the ratio between the externality and its own human capital. In order to see this we drop the indices 
of (8) and define the externality ratio $\xi=\bar{h} / h$ such that the growth rate for $\eta=1$ is given by

$$
g=L \cdot[\epsilon \xi+(1-\epsilon)]^{1-\alpha}-L \frac{\bar{c}}{h}
$$

The growth rate is determined by two terms. The second term reduces the growth rate and it is large for poor countries (i.e. when $h$ is low) and vanishing for rich countries. Intuitively, education expenditure is relatively low because subsistence needs are relatively important in poor countries. The first term depends on the externality ratio $\xi$. For an initially poor country we have $\xi>1$ because the country is poorer than the average of its neighborhood. The fact that $\xi>1$ is favorable for growth does not necessarily imply that poor countries catch up quickly. Firstly, as stated above, the second term is large for the poor country, especially immediately after take-off. Secondly, the average neighborhood may actually grow at a higher rate because it is favorably linked to rich countries implying an increasing $\xi$. Altogether this means that growth is increasing during the early phase after the take off. As the country gets richer, the second term vanishes and $\xi$ will eventually decline to unity as the country converges towards the steady state. A typical S-shaped growth rate is therefore driven by an increasing $\xi$ in the beginning. For the moment we assume that $\xi$ increases monotonically to a maximum and then decreases (thereby excluding oscillating behavior). For all networks investigated below it turns out that $\xi$ behaves in this way.

Proposition 5 (S-shaped Transitions). Given a steady-state of long-run growth $g^{*}$ exists. Let the externality ratio $\xi(h)$ of a country be twice continuously differentiable, concave and increasing in $h$ to a maximum. Then there exists a $T \in\{0,1, \ldots, \infty\}$ such that the country's growth rate changes from accelerating to decelerating.

Recall that both neoclassical growth theory and Romer's (1986) endogenous growth theory fail to predict the gradual take-off to growth (the new Kaldor fact number 2). The neoclassical model predicts that growth is highest for the poorest countries, i.e. for the countries farthest away from the steady-state. This counterfactual feature follows immediately from decreasing returns of factor accumulation. According to the linear Romer (1986) model there are no transitional dynamics. The original Romer (1986) article - in contrast to its textbook presentations also discussed the case of accelerating growth rates by assuming increasing returns to scale. This mechanism, however, leads to explosion of the economy without further assumption that 
stops growth rates from growing. Growth is not s-shaped. The present model, in line with the historical observation, generates s-shaped transitions. The growth rate of GDP per capita accelerates gradually during the first phase after the take off. During the second phase growth decelerates, a phenomenon which renders convergence towards the steady-state.

Proposition 6 (Overshooting Growth). Assume that $\overline{\mathbf{W}}$ is connected and a steady state of long-run growth $g^{*}$ exists. A) Forerunners of the industrial revolution converge monotonously towards $g^{*}$. B) Followers of the industrial revolution converge non-monotonously at growth rates that are temporarily above $g^{*}$ if their initial lag of human capital with respect to the neighborhood average is sufficiently large.

Intuitively, overshooting growth occurs when initially backward countries start investing into education and there is a lot to learn from the rest of the world or, more precisely, from the countries to which a link of mutual knowledge exchange exists (i.e. the neighbors). The opportunity to tap into a greater pool of knowledge creates an advantage of backwardness (Gerschenkron, 1962). In line with the historical evidence the initially backward countries manage to double their income per capita in much shorter time than the leaders of the industrial revolution (Parente and Prescott, 1994, 2005). ${ }^{6}$

Overshooting growth of backward countries is essential for world inequality to decline. In order to address the evolution of world income inequality properly it is important to distinguish relative income inequality, measured by country income relative to world income and expressed by the Gini-coefficient (or the Theil index) and absolute income inequality, measured by the difference of absolute income levels between pairs of countries.

Proposition 7 (The World Kuznets Curve). Assume $\overline{\mathbf{W}}$ is connected and a steady state of growth $g^{*}$ exists. A) Relative income inequality between countries vanishes eventually. The Gini-coefficient converges to zero. B) If initially some countries grow and others stagnate, then relative income inequality increases initially and declines subsequently.

Proposition 8 (No Convergence in Levels). Assume $\overline{\mathbf{W}}$ is connected and a steady-state of growth $g^{*}$ exists. Despite eventually declining world inequality there is not necessarily convergence of income levels.

\footnotetext{
${ }^{6}$ Parente and Prescott $(1994,2005)$ offer an alternative explanation of the phenomenon. According to their theory world knowledge grows at an exogenously given rate and adoption of world knowledge is easier for a country when it is farther away from world knowledge because barriers to adoption are smaller.
} 
The model produces not only a Great Divergence (Pommeranz, 2000), initiated by the take off of the leaders of industrial revolution, but also a "Great Convergence", which follows after the take off of the latecomers off the industrial revolution, i.e. those countries that take off latest because of inferior initial endowments and missing links to the forerunners of the industrial revolution. Recall that the a connected network ensures existence of a steady-state. This means that eventually all knowledge is shared between all countries, which explains the phenomenon of vanishing relative income inequality. This result is in disagreement with some popular articles on the world income distribution (Jones, 1997, Acemoglu and Ventura, 2002) but it is in line with Lucas $(2000,2009)$ vision of the world's future development. Notice that the prediction that relative income inequality vanishes eventually does not imply that absolute income levels converge. In fact, as we show later, countries may even overtake each other (several times) while income inequality measured by the Gini- or Theil-index disappears. In order to investigate this phenomenon and other interesting features we turn next to a numerical presentation of the model.

\section{Adjustment Dynamics: The Great Divergence And The Great Convergence}

We assume that initially there are at most two distinct groups of countries. A small group of countries with relatively high human capital endowment (the rich) and a large group with relatively low endowment (the poor). Initial endowments are such that the rich countries are growing, albeit at a very low rate, while the poor countries are stagnating because aggregate productivity is so low that investment in human capital is not worthwhile. This setup is the most interesting case because it allows for evolving country heterogeneity. As time proceeds and knowledge crosses borders, income and productivity of the countries grow differently according to their connections with other countries and countries become more dissimilar with respect to economic growth. Having two different groups of countries is the minimum setup to discuss evolving heterogeneity (cf. Proposition 2).

4.1. Stylized Networks. We first investigate adjustment dynamics for some particularly simple examples of the externality matrix $\overline{\mathbf{W}}$. This allows us to provide straightforwardly an understanding of the main mechanism behind the international flow of knowledge and world income dynamics. Suppose the world network is given alternatively by a stylized network from the set of networks depicted in Figure 2. Rich countries, i.e. countries in which the population 
is better educated, are represented by red circles and poor countries are represented by blue squares. ${ }^{7}$

A bridge network is partitioned into two components. The rich and the poor are each internally representing a complete network. The two components share exactly one link, the bridge. The bridge network could be understood as a metaphor for a world of different continents connected by a minimum of links.

Figure 2: Stylized Networks

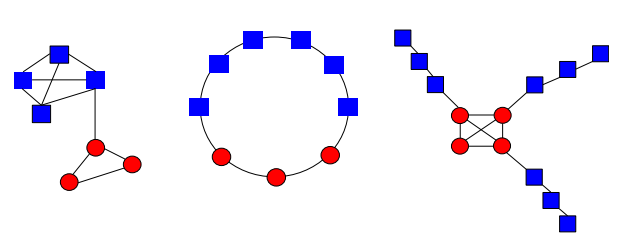

Stylized networks: Bridge (left), Ring (middle). Core-Periphery (right). Rich countries are represented by red circles and poor countries are represented by blue squares.

A ring network is obtained by positioning each country along a line, ordered by country-specific human capital. In order to get a symmetric architecture the line is closed to form a circle. Each country is connected to its $k$ nearest neighbors (not counting itself as neighbor). This means that there are $2 k$ poor countries connected with rich countries. In the example we have $k=1$. The ring network emphasizes the role of geographic proximity for knowledge exchange. The world is "round" and countries are directly connected only with their geographical neighbors.

Finally we consider the core-periphery network. Here, the core consisting of initially rich countries forms a complete network to which a number of peripheries consisting of initially poor countries are connected. The poor countries are connected in series implying that there is one bridge per periphery, linking it with the core. The core-periphery network describes a situation in which a subset of rich countries is already fully integrated and another subset of poor countries (the colonies) is less well integrated.

4.2. Numerical Specification. We begin with a benchmark specification of the model. Later on, we discuss the sensitivity of results on parameter choice. Suppose the world consists of 100 countries of which 10 percent are initially rich, i.e. better endowed with human capital. We do not ask where the initial differences between countries come from but assume, in line with the historical evidence on economic conditions in pre-modern times, that the initial differences are

\footnotetext{
${ }^{7}$ In the Appendix we provide the networks in matrix notation.
} 
small. The challenge is thus to explain how a great variety of growth performances evolves out of small initial differences.

All countries share the same parameters values. We set $\eta=1$ in order to allow for long-run growth. We set $\alpha=0.5$, such that at the steady-state productivity growth explains half of GDP per capita (approximating the findings by e.g. Barro and Sala-i-Martin, 2004 and Easterly and Levine, 2001). We set the utility weight for children's income to $\beta=0.23$ such that at the steady-state 7 percent of income are spent on education, as observed approximately for most fully developed countries (Eurostat, 2012). We then adjust the value of $B$ such that the implied steady-state growth rate is 2 percent annually. The parameter values of $\epsilon$ and $\bar{c}$ are irrelevant for the steady-state but shaping adjustment dynamics. Eaton and Kortum (1999) estimate, for a sample of fully developed countries, that between one half and three-fourths of the knowledge adopted has been generated abroad. We take the benchmark value for our (temporarily) more heterogenous set of countries from the lower bound of their estimates and set $\epsilon=0.5$. This means that one half of the knowledge available in a country has been generated by domestic firms and the other half stems from international knowledge diffusion. We set $\bar{c}=0.33$ in order to get the best fit of economic growth of the leader country with the historical data.

After running the simulation we convert the generational data into annual data assuming that a generation takes 20 years. We convert generational growth rates into annual ones for better comparability with real data. We set initial time to the year 1700 , i.e. shortly before the onset of the first industrial revolution. The poor countries are endowed with minimum human capital, $h_{\text {poor }, 0}=1$. The rich countries are assumed to be 20 percent better endowed $h_{\text {rich }, 0}=1.2$. This implies that - depending on the respective network - income in the rich countries is initially 1.23 to 1.3 times higher than in poor countries. These values correspond well with the estimates of the head start of the Western European countries vis a vis the rest of the world at the dawn of the first industrial revolution (Bairoch, 1998, Ch. 9). Most importantly this specification means that the poor countries are initially stagnating while the rich countries are initially growing at a low rate of around 0.3 percent.

Figure 3 shows the evolution of growth predicted by the numerical experiments. The upper panel assumes that the world network is a bridge. Knowledge diffusion through the network generates four visibly distinct adjustment trajectories. Naturally, the rich countries take off first. The rich country directly linked to the poor world takes off a bit later because there is 
Figure 3: Evolution of Economic Growth in 100 Countries when the World is a...
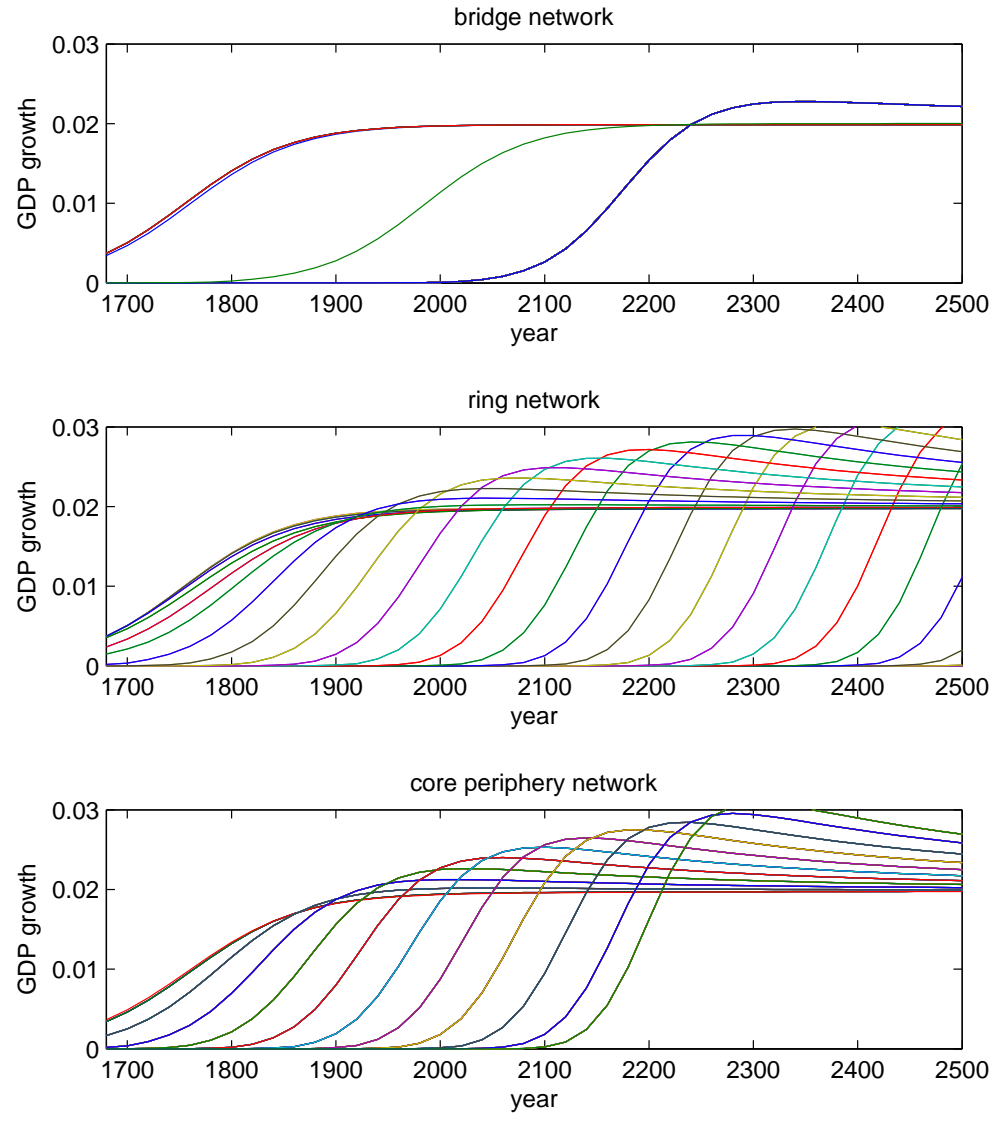

For all three "worlds": $10 \%$ of countries initially better endowed with human capital (in 1680). $h_{0}=1$ for poor countries, $h_{0}=1.2$ for rich countries. Parameters: $\alpha=0.33, \beta=0.4$, $\eta=1, \bar{c}=0.33, \epsilon=0.5$. Middle panel: 2 neighbors per node. Bottom panel: 9 peripheries a 10 countries.

less to learn from the poor neighbor. In contrast, the poor country equipped with a direct link to the rich world experiences a huge advantage vis a vis its poor neighbors and takes off about two centuries earlier, fueled by knowledge diffusion from its rich neighbor. The remaining club of less developed countries takes off late but experiences an "advantage of backwardness" (Gerschenkron, 1962) in the sense that income growth surpasses income growth of the forerunners of the industrial revolution.

The fact that growth rates of latecomers overshoot means that income inequality declines eventually. The reason for declining income inequality is that latecomers, once growth is initiated, tap into a greater reservoir of world knowledge. This knowledge has been accumulated in the recent past and was not yet available when the forerunners took off. This phenomenon relates the model to the new Kaldor fact no. 1: the increasing flow of ideas via globalization. 
Globalization here means that an increasing share of countries gets out of stagnation with education becoming worthwhile and that the educated workforce benefits from and contributes to an increasing stock of knowledge diffusing through the network.

The bridge network displays already one important phenomenon of growth in networks, the overshooting growth of latecomers, but it generates too little variety of economic performance across countries. This is different for the ring network, as evidenced in the center panel of Figure 3. The initially rich countries are again experiencing a very similar take off to growth, in which the countries surrounded by other rich countries perform only slightly better than those at the border to the poor world. The poor countries, on the other hand, experience a very varied take off. The reason is that new knowledge is "handed over" along the circle. The two countries neighboring the rich take off first among the poor, then the countries next to these countries follow etc. There is also more variety in growth rates. Generally we observe that overshooting growth is the higher the later the take off time. This is so because there is more to learn from the neighbors once education becomes worthwhile for the latecomers. Consequently, growth during the early take off phase is much faster for latecomers. While it took about 200 years for the forerunners of the industrial revolution to reach a growth rate of 2 percent, the countries taking off in the 1950s needed only about two generations to achieve the same rate of growth.

Compared with other networks the circle predicts a very long period of take offs, implying a very long period of increasing world inequality. The reason is that it takes a lot of time until knowledge is passed on along the circle from neighbor to neighbor toward the most unfortunate country "at the other side of the world". Moreover, the take offs are "too predictable". Their sequence follows the position of countries on the circle.

The core-periphery network, shown in the bottom panel of Figure 3, eliminates some of the flaws of the two previous networks. It produces a variety of growth experiences, largely overshooting growth rates, and a reasonable duration of the "era of take offs to growth" from 1700 to the mid 21st century. Yet the growth experience of countries is still too easily predicted. The countries next to the bridges to the core take off just after the initially rich and then we observe departures from stagnation according to the order of countries along the peripheries. Altogether we observe "only" 10 different growth paths, one for the core countries and one for each position on the periphery. There is still too little heterogeneity in the world. Moreover, the connectivity between the initially rich countries is "too high" in all three simple networks. 
This is evident from the result that the take-off of the forerunners of the industrial revolution happens too fast in all three panels of Figure 3. By the year 1800 the forerunners of the industrial revolution are counterfactually predicted to grow already at a rate of 1.5 percent annually.

\section{Knowledge Diffusion and Income Evolution in A Small World}

5.1. Model Setup. The small world model (Watts and Strogatz, 1998) is a device to investigate in a simple way an irregular network that features both local connectivity and long-distance links between nodes. It is easily understood mathematically but complex enough to allow for an application to a plethora of biological and social phenomena (see Newmann, 2003, for an overview). The small world model appears to be particularly suited for our purpose because it retains the importance of local connectivity, capturing the fact that most knowledge diffuses from direct neighbors, but allows at the same time to establish long-distance links between distant countries.

Here we consider an extension of the Watts and Strogatz model, developed by Newman et al. (2000), which appears to be more appropriate for our purpose. The idea of the Small World model can be illustrated best by considering a network on a one-dimensional lattice. It is constructed from a regular network in which any node (country) is connected with its direct neighbors that are $m$ or fewer lattice spaces away. In the example of Figure $4, m=2$. Each country is connected to 4 neighbors, 2 at each side. The regular network is then modified by randomly adding long-distance links. The probability for a long-distance link per link of the underlying lattice is denoted by $p$. The middle panel of Figure 4 shows an example for which $p$ is low, the panel on the right shows an example for larger $p$.

Figure 4: Small World Network
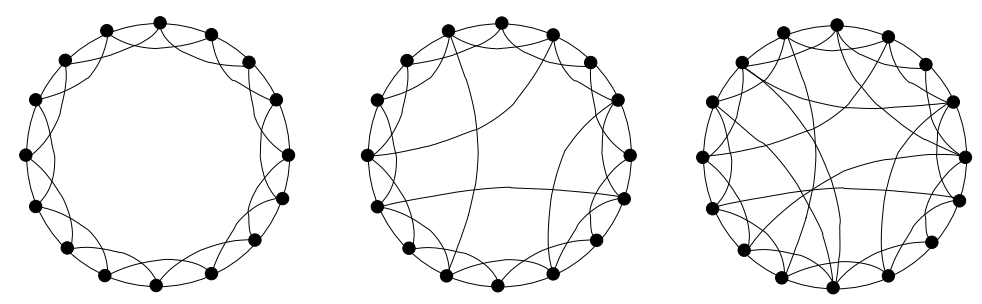

For international knowledge flows the feature of local connectivity, created through positioning the countries on a ring, captures the empirical fact that knowledge spillovers, in principle, decline with geographic distance (e.g. Keller, 2002). The presence of long-distance links means 
that this generality is occasionally broken and that then effective distance is (much) shorter than geographic distance. Figuratively speaking we could imagine the US to be geographically only two neighbors away from Guatemala but exchanging much more knowledge with England because both countries are connected with a long-distance link. This may turn out to be crucial for comparative development because the US benefits directly from knowledge created in the England while Guatemala benefits only indirectly via the US. Moreover, in order for the knowledge to arrive in Guatemala it has to cross Mexico, another initially less well educated country, such that a part of the knowledge created in England gets "lost in transition".

5.2. Results for the Benchmark Model. As a benchmark we take the specification of the economic model from above and consider $p=0.3$, i.e. the case in which 30 percent of the countries are equipped with a long-distance link. We subsequently provide sensitivity analysis with respect to $p$ and other important parameters. Figure 5 shows the implied adjustment dynamics for the benchmark case. In contrast to the simple networks discussed above, the small world generates a lot of heterogeneity. Basically, each of the 100 countries follows its own idiosyncratic growth trajectory. Recalling that initially, in the year 1700, there were only two different types of countries and that the initial difference between rich and poor countries was small (1:1.2), we conclude that diversity evolves out of similarity.

Comparing the model prediction with the historical facts (Bairoch, 1993; Galor, 2005), we would imagine the group of initially rich countries as Western Europe, which reaches on average a growth rate of 1 percent in 1820-1870, that is during the phase in which some of the Latin American countries started to grow. In the 20th century, when the latecomers take off, the initially rich countries grow at an almost constant rate of 2 percent annually. It is also interesting to observe that growth of the leaders is already surpassed by growth of some followers in 19th century and that, despite the presence of long-distance links, a few countries are predicted to take off very late in the mid 21 st century. The differentiated and relatively rapid take offs of the latecomers of the industrial revolution in the 20th century produce the picture of a great variety of subsequent growth experiences of countries that were almost equally poor just a generation ago.

The middle panel of Figure 5 shows the implied average economic growth in the world. Dots represent the data points from De Long (1998) shown in Figure 1. The model gets the take off of aggregate world growth about right. World growth rises from almost zero to just below 1 
Figure 5: Evolution of Economic Growth in 100 Countries in a Small World
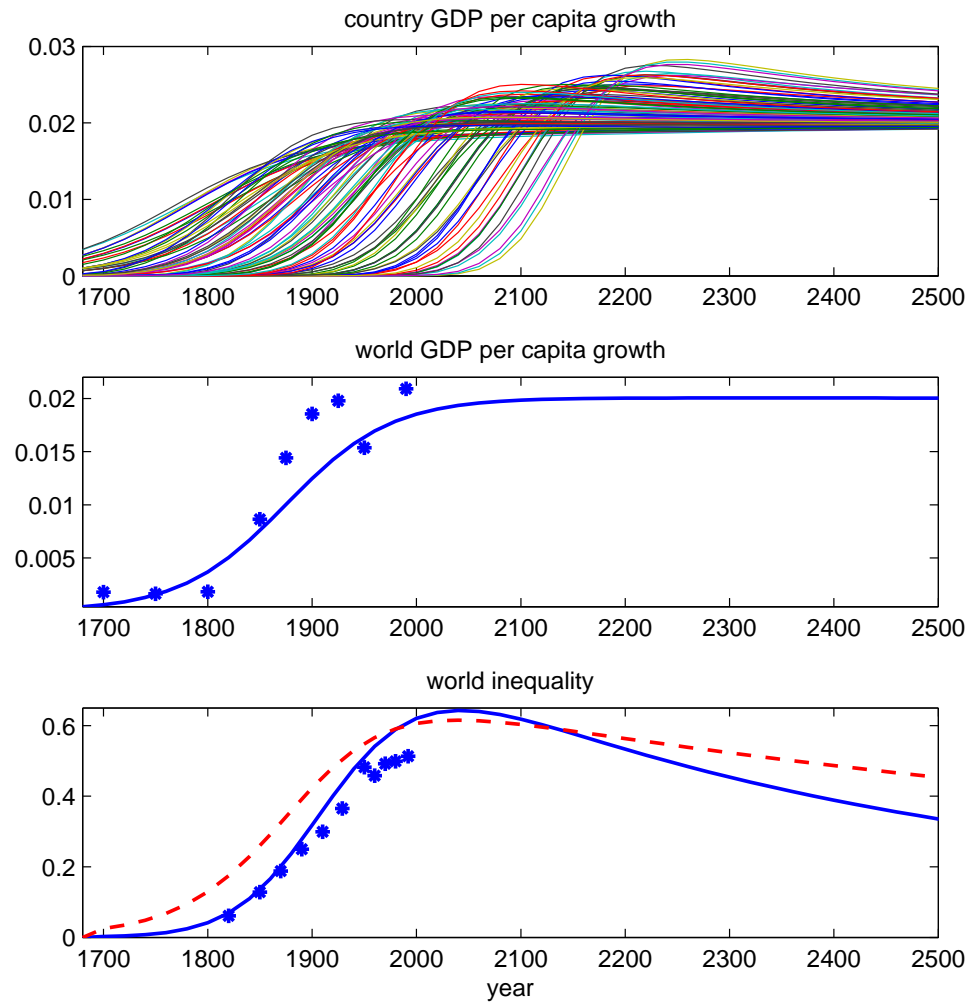

Dots in middle panel: world GDP growth according to De Long (1998); Bottom Panel: solid line: Theil-index; dashed line: Gini-index; dots: Theil index according to Bourguignon and Morrison (2002). Parameters as for Figure 3; ring with 1 neighbor to left and right hand side; rewiring probability 0.3 .

percent in the mid 19th century and to about 1.5 percent in the mid 20th century. Compared to the data the take off is somewhat too slow, an outcome that could be corrected (by assuming a higher $p$ or $\epsilon$ ) at the expense of predicting a "too early" take off of the latecomers. Altogether however, the model generates plausible s-shaped transitions. On the individual level, as well as on the global level, the model provides an explanation for the new Kaldor fact no. 2, the gradual increase of the rate of economic growth.

The differentiated take off of countries produces the Great Divergence (Pommeranz, 2000) world inequality increases strongly from 1800 to 2000. This is shown in the lower panel of Figure 5, in which dots represent the data points from Figure 1 (Bourguignon and Morrison, 2002). The solid and dashed line, respectively, show the model's prediction for the evolution of the Gini-index and the Theil index, computed from the individual income trajectories of the 100 countries. According to the model, for its benchmark calibration, inequality stops growing in the 
late 20 th century. From the early 21 century onwards the model predicts a "Great Convergence". As more and more latecomers catch up with overshooting growth rates, world inequality declines. The inequality curve, however, is skewed. The Great Convergence is predicted to take several centuries longer than the Great Divergence. The intuition is straightforward. The fact that the original leaders of the industrial revolution keep growing makes the catch up harder than the quick departure of the leaders from the almost stagnant income of the followers and latecomers two centuries earlier.

5.3. The Evolution of TFP across Time and Space. With rising income, households spend more on education, in line with the new Kaldor fact no. 5. The share of income spent on education converges gradually towards 7 percent of GDP. Increasing education at home as well as abroad means that aggregate productivity (TFP) also increases. TFP of country $i$ at time $t$ is given by $A_{i t}$. In order to explore the evolution of TFP growth we have sorted the countries for any time $t$ into income quintiles, with the poorest 20 percent of countries in the first quintile and the richest 20 percent in the 5 th quintile. We then computed the average growth rate of TFP for each quintile.

Figure 6 shows excerpts of the computation for two specific years, 1820 and 1960. In line with the historical evidence, TFP growth, compared to contemporary rates, was low in the 18th century, even for the leaders of the second industrial revolution (Crafts, 2003). According to the model, TFP growth was about 0.8 percent for the richest countries and about 0.2 . in the second richest income group. That TFP growth is predicted to be lower in poorer countries comes at no surprise. It is perhaps more interesting to observe that growth of TFP is increasing over time across all income groups. This is so because at earlier times in history more countries had neighbors who were not yet well educated and produced little new knowledge. This means that average knowledge was low, and that, on average, comparatively little new knowledge diffused internationally. In general, as evidenced by Figure 5 and 6 taken together, the model captures the new Kaldor fact no. 4, the large income and TFP differences across countries.

The variability of growth rates is shown in Figure 7, again exemplarily for 1820 and 1960. The figure shows the standard deviation (in percent) of TFP growth for each income quintile. The panel for the year 1960 corresponds with the new Kaldor fact no. 3, stating that the variance of growth rates across countries increases with distance to the technological frontier. Since there has been only few take offs in the bottom quintile in the 1960s, the highest standard deviation is 

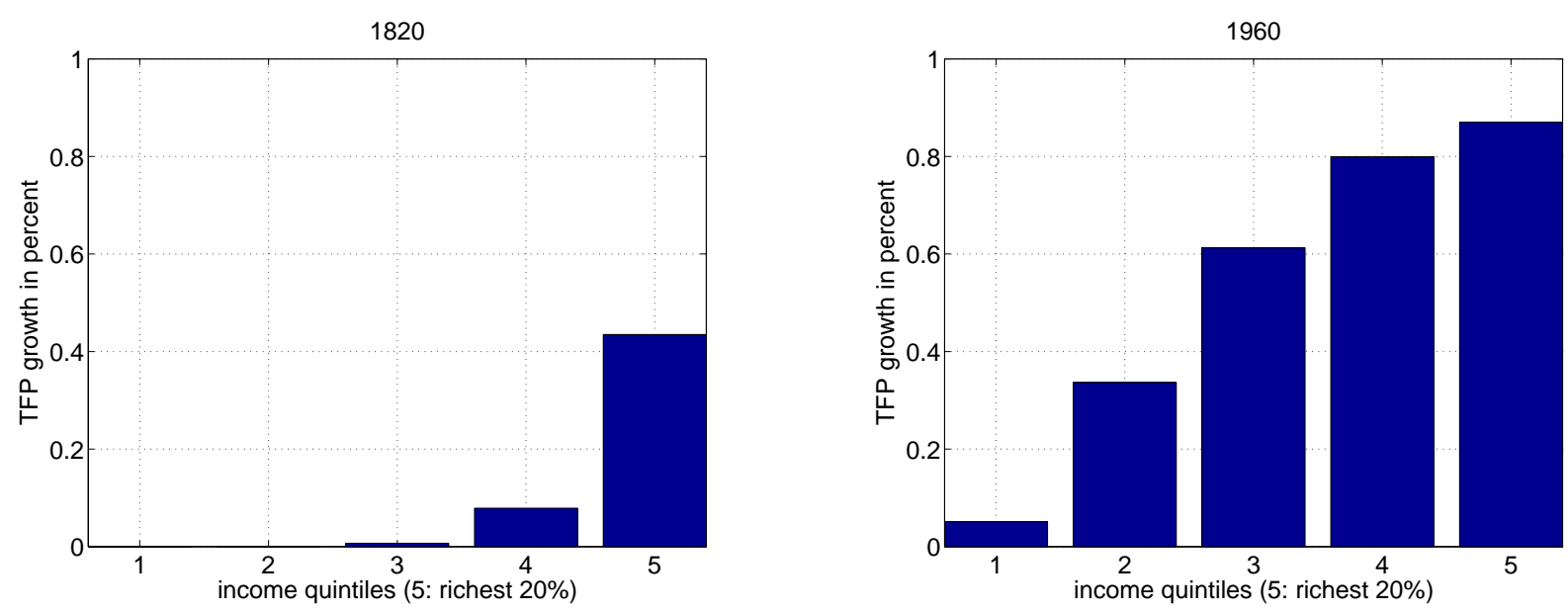

observed for the second poorest income group. But otherwise the variance is subsequently lower among the richer groups. The figure also suggest, that fact no. 3 is a phenomenon of the 20th century. In the 19th century when the frontier countries themselves experienced sequentially their take-offs to growth, while the rest of the world was still close to subsistence, the variance of growth rates was highest among the richest countries.

Figure 7: Standard Deviation of TFP Growth Across Countries
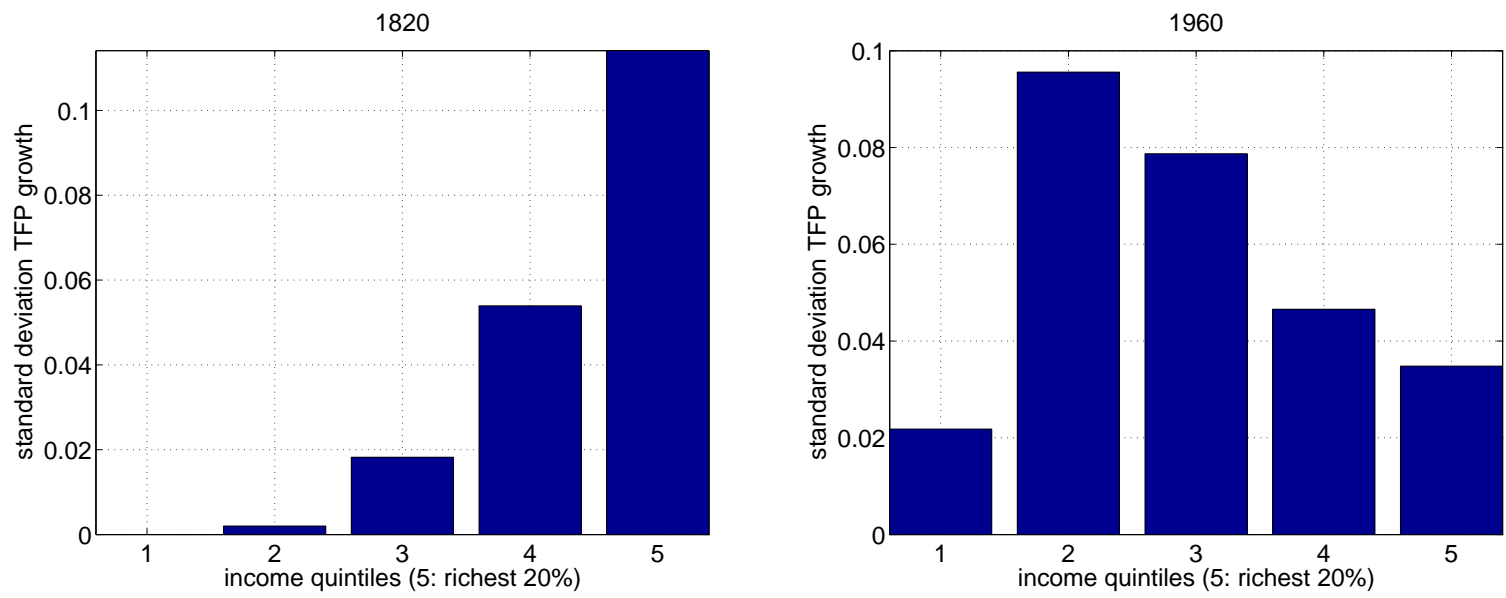

\subsection{Is the Present World Income Distribution Close to Its Steady State? As ev-}

idenced in Figure 5 the model predicts that relative income inequality across the world will eventually decline after the take off of the latecomers of industrialization. In contrast to such an optimistic outlook, some related studies developed theories in order to explain a constant world income distribution at a state of high inequality, most notably perhaps the study of Acemoglu and Ventura (2002). Acemoglua and Ventura's work was inspired by the observation of 
"a relatively stable" world income distribution in the second half of the 20th century.

Figure 8: Income Relative to Leader: 1960 vs. 2000

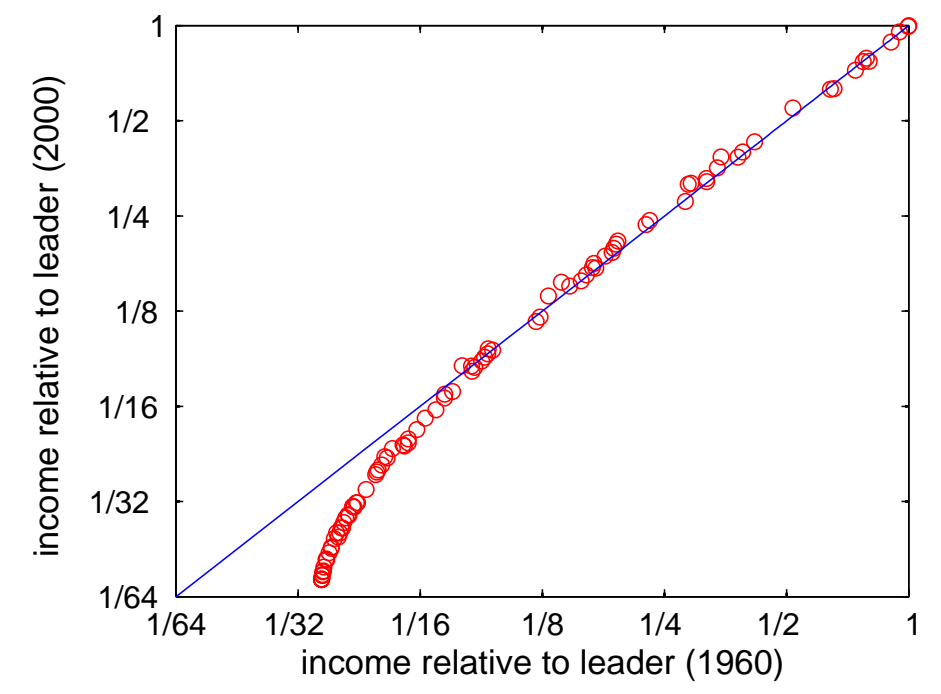

Country GDP relative to leader country Benchmark model; loglog scale.

A "relatively stable" distribution, however, could be inferred also from an actually slowly evolving distribution, in particular if the window of observation is relatively short and if the observation happens to be taken at a period of time when world inequality is flat because it is close to its maximum. In order to verify this claim by way of example we compute for the outcome from the benchmark economy a relative income plot similar to the one displayed in Jones (1997, Figure 2) and Acemoglu and Ventura (2002, Figure 1). Specifically we compute from the time series shown in Figure 5 for all countries the relative income with respect to the leader country in the year 1960 and in the year 2000 and plot the result on a loglog scale, as shown in Figure 8. In accordance with the earlier studies we observe little deviation from the 45 degree line. Relative income in 1960 is a good predictor of relative income in 2000 . Confronted with this picture alone, one could indeed be tempted to conclude that the world income distribution is basically constant. In fact, however, we know from Proposition 7 that income relative to the leader country moves to unity for all countries as time goes to infinity. This convergence process, however, is very slow and presumably not discernable within a 40 year time window. The observation of an almost stable distribution of high inequality is consistent with an actually moving distribution toward equality. 
5.5. Overtaking and Falling Behind. The phenomenon of income convergence of countries is at the center of modern growth economics. The phenomenon of overtaking however is rarely investigated in the context of an economic growth model. ${ }^{8}$ Since overtaking and falling back of countries is observed in the real world it is challenging to model this behavior while not relying on stochastic (i.e. unexplained) fluctuation and not giving up global stability, i.e. convergence to a global steady-state with vanishing income inequality. To demonstrate this extraordinary behavior we perform the following numerical experiment. We follow the 10 initially rich countries, named $1,2, \ldots, 10$, along the way towards the steady state and visualize their relative position in the world income ranking. Figure 9 shows the resulting "income ladders" for four different years. For example, a dot at the $(1,10)$ position in the 1800 diagram means that country 1 was ranked 10th place in the year 1800 .

\section{Figure 9: World Ranking Position for Country 1 - 10}
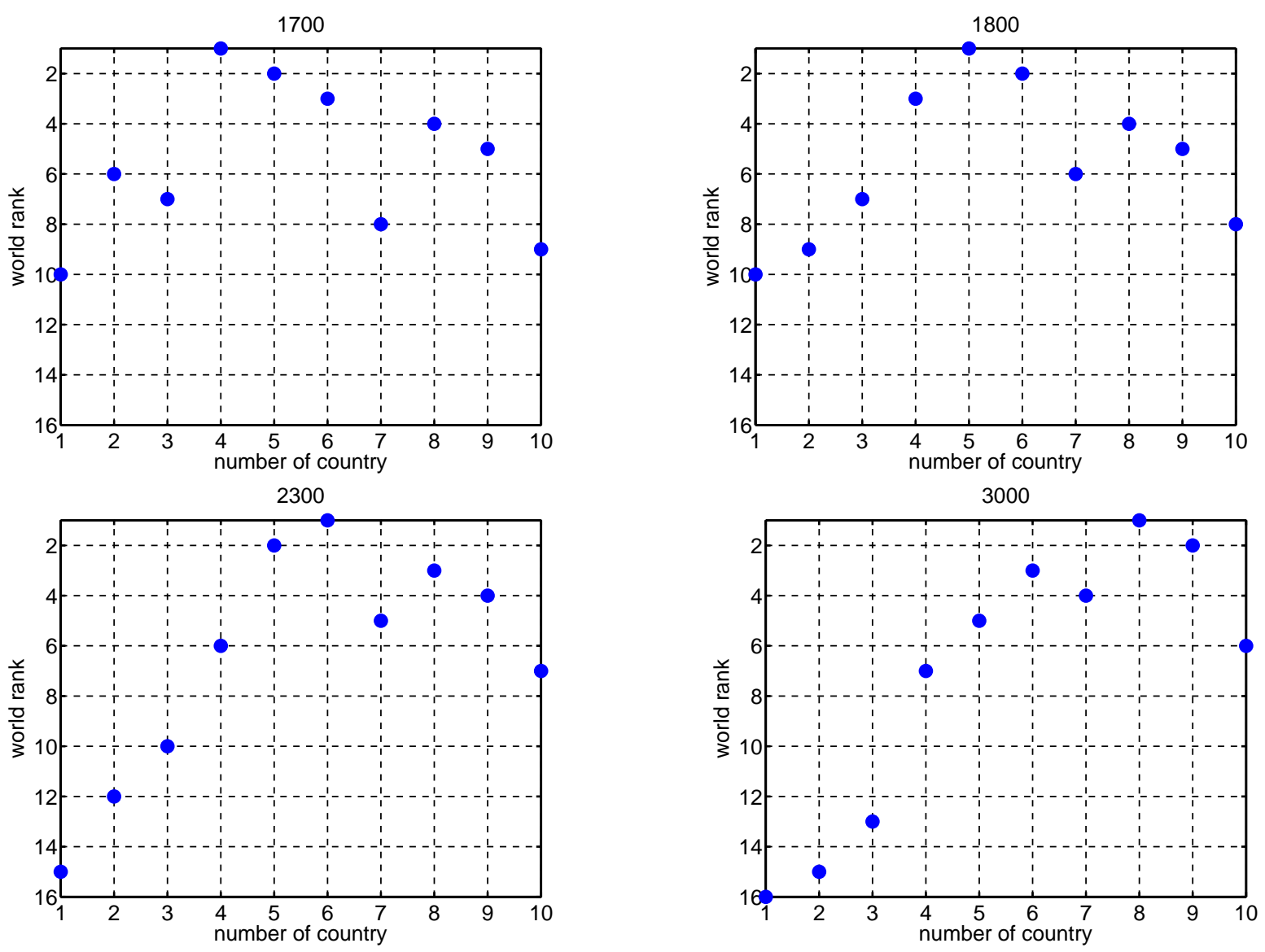

In the numerical experiment, country 4 leads the world income ranking in the year 1700 .

${ }^{8}$ Some researchers modeled overtaking in a purely stochastic context of Markov chains of income distributions, see e.g. Jones (1997). 
Obviously it was favorably connected with other rich countries. By the year 1800 country 4 gave up the lead to country 5, which presumably benefitted from favorable connections with quick followers of the industrial revolution. We also observe that country 2 and 3 fall behind whereas country 7 advances by two positions. In 2300, country 6 is at the top and the original number one dropped to the sixth place while country 1 and 2 fell out of the Top 10 altogether. And in the year 3000 we observe yet another leader, country 8, as well as a new number 2 , country 9 , while country 3 also left the top 10 . These changes in rank are explained by the changing advantage of links as knowledge is accumulated and diffused through the network. For example, an initially rich country connected only to another initially rich country, which in turn is connected only to latecomers of the industrial revolution, grows initially fast and then slows down. It is potentially overtaken by a country that is connected with initially poor countries which, however, are well connected and "infected" by the growing knowledge of their neighbors at an early stage of the diffusion process.

In order to develop an intuition for these results, consider a "network" of two countries, one with initial human capital level $h$ the other with initial human capital level $h+\Delta$. Neglecting the corner solution, the equation of motion (8) for the first country is given by $f_{1}(h, h+\Delta)=$ $L\left\{[\epsilon(h+\Delta)+(1-\epsilon) h]^{1-\alpha} x^{\alpha}-\bar{c}\right\}$. For the second country it is given by $f_{1}(h+\Delta, h)=$ $L\left\{[\epsilon h+(1-\epsilon)(h+\Delta)]^{1-\alpha}(h+\Delta)^{\alpha}-\bar{c}\right\}$. Consider the implausible yet illuminating case in which all knowledge comes from abroad, i.e. $\epsilon=1$, and human capital is not a stand-alone production factor, i.e. $\alpha=0$. In this case, the two economies have changed their roles in the next period. Now the first country is the better endowed one but it keeps this status only for one period after which the advantage is again transferred to the second country. There is overtaking in every period.

Generally, overtaking seems to be more likely the greater $\epsilon$ and the lower $\alpha$. To verify this claim for the simple example, take a first order Taylor approximation around $\Delta=0$ and compute $f_{1}-f_{2}=L \Delta(2 \epsilon(1-\alpha)-1)$. This expression becomes positive, indicating overtaking, for $\epsilon(1-$ $\alpha)>1 / 2$. For the actual model with a complex network of one hundred participating economies we cannot obtain a simple condition for overtaking. Numerically, we find that overtaking is a relatively rare phenomenon for plausible parameter values. The intuition obtained from the simplified example remains, of course, true. A high importance of international knowledge spillovers (high $\epsilon$ ) and a low importance of national education (low $\alpha$ ) make takeovers more 
likely.

5.6. Network Effects on Global Inequality and Growth. We next investigate how the specific make up of the network affects the evolution of the world income distribution. For that purpose we focus on two characteristic numbers, the calendar time when the last country takes off from stagnation and the maximum Gini coefficient reached during the transition. Since long-distance links are set at random in the small world model, we ran each specification of the model 1000 times and took averages afterwards.

Figure 10: Inequality and Growth - Degree of International Knowledge Diffusion
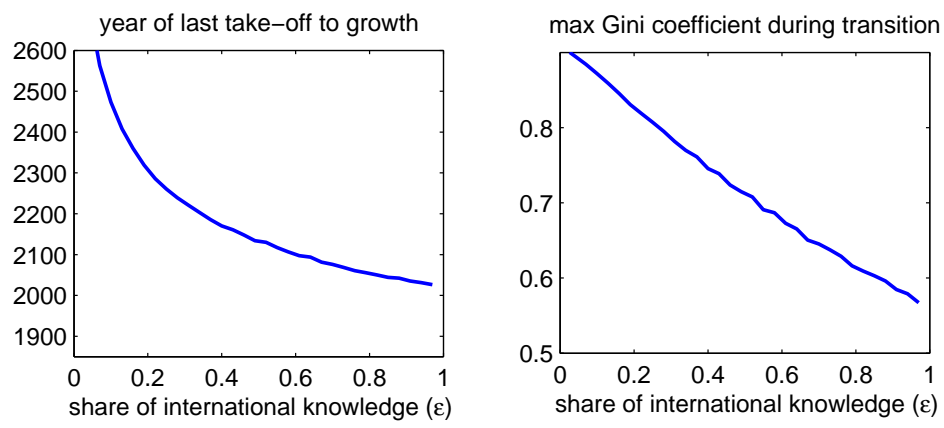

Example with 100 countries; 10 percent initially rich, $p=0.3$, varying $\epsilon$.

Figure 10 shows that a large contribution of international knowledge flows to productivity (that is large $\epsilon$ ) increases the pace of world development. Larger international knowledge spillovers are helpful to reduce world-wide inequality faster because a greater share of the initial knowledge advantage of the leaders is passed on through the network. The original Romer (1986) model is a knife-edge case since there will never be convergence for $\epsilon=0$, that is in isolation. When no knowledge flows towards the initially poor countries, they do not escape from stagnation (without exogenous impulse) and the world remains at an asymmetric equilibrium in which only the club of rich countries is growing.

We next investigate in Figure 11 how the share of long-distance links affects the evolution of the world income distribution. The year of the last take-off decreases very quickly for low values of $p$ but remains rather insensitive for $p$ 's larger than 0.5 . The outcome reflects a well known feature of the small world model, namely that average path length between nodes decreases sharply at low values of $p$ and not much at high values (Watts and Strogatz 1998). Maximum inequality also decreases sharply with increasing $p$, in an almost linear way. If every country had 
Figure 11: Inequality and Growth - Share of Long-Distance Links
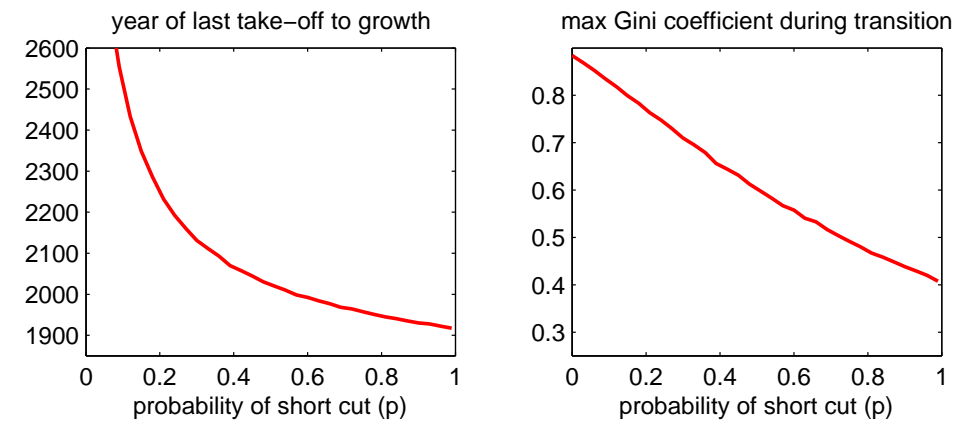

Example with 100 countries; 10 percent initially rich, $\epsilon=0.5$, varying $p$.

a long-distance link $(p=1)$, the last take-off would have been, according to the model, around the year 1900 with an associated maximum Gini coefficient of $0.4 .^{9}$

\subsection{Was an Industrial Revolution Inevitable? - The Role of Network-Geography.}

So far we focussed on a specification of the economic model in which there is always long-run growth. In this section we show that there exist also a non-negligible range of parameter values for which long-run growth happens sometimes. The specific design of the network becomes decisive for long-run economic success. This phenomenon allows us to shed new light - from a geographic perspective - on the question whether an industrial revolution was inevitable (Jones, 2001). Specifically we will show that a sufficiently high connectivity between the initially rich countries can be decisive for industrialization. Only then is it possible to learn sufficiently fast from each other such that a persistent take off to growth becomes possible. Figuratively speaking, if the Western European countries were disconnected from each other or if Europe were disconnected from Asia, industrialization may not have materialized. These results provide a network foundation for Diamond's (1997) arguments on the importance of geography for longrun human development.

In order to demonstrate this kind of network-based indeterminacy we increase $\bar{c}$ from 0.33 to 0.37 and keep all other parameter values from the benchmark model. The increased value of $\bar{c}$ makes consumption somewhat more important at low levels of income, implying that education increases less steeply when income rises. This means that the take off from stagnation for any

${ }^{9}$ It can be shown that the year of the last take-off and the maximum Gini depends also quite strongly on the share of initially rich countries. The initial income ratio between rich and poor countries, in contrast, does not much affect the speed of transition and maximum inequality. The reason is that the negative impact on income inequality of an initially higher income gap is almost completely balanced by the fact that more can be learned from the initially better endowed economies. 
individual country is less steep. It can then be that there is no take-off to long-run growth. To see this, consider the unlikely but possible case that all initially rich countries are connected through long-distance links exclusively with poor countries. The poor countries are initially not investing in education, implying that there is no knowledge to be gained from them. With little knowledge diffusion from abroad, it can then be that the human capital endowment at home taken for itself is insufficient to sustain growth, that is the associated income is too low to sustain the initial level of human capital, a fact which initiates the return to stagnation.

In order to demonstrate this phenomenon we ran each economy 1000 times with randomly selected network structure and counted how many runs managed to arrive at positive long-run growth of average income in the world. Dividing the outcome by 1000 we get the success rate of industrialization. If $100 \%$ percent of the networks arrive at long-run growth, we would say that industrialization was inevitable. We perform this experiment for alternative values of $p$, the share of long-distance links (1000 runs per value of $p$ ). The panel on the right hand side of Figure 12 shows the results. While having more long-distance links is good for a speedy transition and low world inequality if long-run growth happens (see last the section), it can be detrimental for growth to happen at all. If the initially rich countries are not sufficiently well connected with each other, which is the case when the share of long-distance links is large, they benefit less from international knowledge exchange, and the take-off to growth gets harder. For $p \rightarrow 1$ the success rate of industrialization falls to about 10 percent. These were the "lucky" cases in which the initially rich country incidently got long-distance links mostly among themselves.

Figure 12: Success Rate of Industrialization
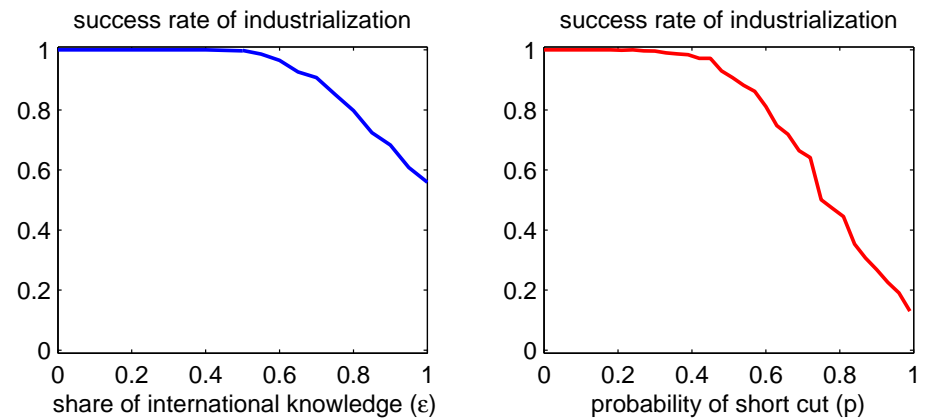

The figure shows for 1000 runs of the same with randomly assigned long-distance links the share of successful runs, i.e. runs converging towards a positive average rate of economic growth across the world. Parameter values as for benchmark model but $\bar{c}=0.37$.

Similar results are obtained when $\epsilon$ gets very large. This is demonstrated in the panel on 
the left hand side of Figure 12 for which we ran the model 1000 times for each value of $\epsilon$ with $p=0.3$. We see that up to an $\epsilon$ of 0.5 industrialization always happens. Then the success ratio begins to decline, ending at somewhat above 50 percent for $\epsilon=1$. The result can be explained with the intuition developed above. For $\epsilon \rightarrow 1$ growth is solely based on knowledge diffusion from abroad. But most countries are initially poor and there is no knowledge gained from them. If the distribution of long-distance links is unfavorable such that many initially rich countries are connected with initially poor ones, knowledge inflows into the rich countries are too small to sustain growth and to transmit it successfully to the poor countries.

There exists also a critical range for the share of initially rich countries. If the share is below 10 percent, the success ratio declines with declining share of initially rich countries. The explanation is again intuitive. If the share of initially rich countries is low, there is little knowledge exchanged internationally, which provides stagnation if the initially rich cannot sustain growth on their own, without knowledge inflows from abroad. ${ }^{10}$

\section{Conclusion}

In this paper we have offered a network-based theory of knowledge diffusion as an explanation for the divergence of countries out of initial similarity as well as for their subsequent global economic convergence. Besides the endogenous evolution of the world income distribution the theory contributes also to the explanation of the new Kaldor facts (Jones and Romer, 2010). The theory generates s-shaped transition paths with gradual take off from stagnation as well as overshooting growth rates at later stages of development. In the long-run it thus predicts (slow) convergence of relative income across the globe.

The model could be straightforwardly extended such that it predicts permanent relative income inequality by assuming that some countries use the available knowledge less efficiently than others. From the perspective of the very long run, however, convergence appears to be more intuitively appealing. Infinite persistence of productivity differences would mean that backward countries could never learn some features of production from the more successful countries, even with infinite time on their hands.

We also considered the question whether industrialization was inevitable from a global network

\footnotetext{
$\overline{10}$ One might argue that historically there was just one industrial leader, England, which pulled the rest of the world out of stagnation. In the Appendix we present a (re-calibrated) case in which just one country initiates the take off to growth and the Great Divergence.
} 
perspective. We showed that some network geographies are more conducive to growth than others. In particular, if the initially better endowed economies are not sufficiently well connected among themselves, long-run growth may not materialize. If long-run growth is possible, however, less local connectivity and more long-distance links are good for a rapid diffusion of knowledge and a relatively early take off of the poorest countries, implying a relatively low peak of world inequality along the way to global growth.

Although the underlying economic model has been a deliberately simple one, the theory generates already a great variety of individual growth performances, including, for example, the takeover of countries in the course of global knowledge diffusion. Naturally, further extensions are conceivable. For example, the reliance on learning-by-doing could be relaxed by introducing a two-state process according to which learning-by-doing eventually triggers market R\&D activities as in Strulik (2009) and Strulik et al. (2013). Another interesting application could be to investigate the spread of the fertility transition through a global network.

In the present paper we conceptualized as globalization the increasing flow of knowledge through the world. The network itself, however, may be subject to globalization as well. This could by captured by an over time increasing share of long-distance links (as in Lindner and Strulik, 2012). The extension towards an evolving network is perhaps the most promising next step in the development of our network-based theory of knowledge diffusion and growth. 


\section{REFERENCES}

Acemoglu, D. and Ventura, J., 2002, The world income distribution, Quarterly Journal of Economics 117, 659-694.

Arrow, K.J., 1962, The economic implications of learning-by-doing, Review of Economic Studies $29,155-173$.

Bairoch, P., 1993, Economics and World History, University of Chicago Press, Hemel Hempstead.

Barro, R.J. and X. Sala-i-Martin, 2004, Economic Growth (2nd ed.), MIT Press, Cambridge, MA.

Boucekkine, R., de la Croix, D., and Licandro, O., 2002, Vintage human capital, demographic trends, and endogenous growth, Journal of Economic Theory 104: 340-375.

Bourguignon, F. and Morrisson, C., 2002, Inequality among world citizens: 1820-1992, American Economic Review 92, 727-744.

Cavalcanti, T. and C. Giannitsarou, 2012, Network structure and human capital dynamics, Working Paper, University of Cambridge.

Comin, D. A., Dmitriev, M., and Rossi-Hansberg, E., 2012. The spatial diffusion of technology, NBER Discussion Paper 18534.

Crafts, N.F.R., 2003, Quantifying the contribution of technological change to economic growth in different eras: a review of the evidence, Economic History, London School of Economics and Political Science.

De Long, B., 1998, Estimates of World GDP, One Million BC - Present. University of California, Berkeley, Department of Economics, http://delong.typepad.com/print/20061012_ LRWGDP.pdf.

Diamond, J., 1997, Guns, Germs, and Steel: The Fates of Human Societies WW Norton, New York.

Doepke, M., 2004, Accounting for fertility decline during the transition to growth. Journal of Economic Growth 9: 347-383.

Easterly, W. and Levine, R., 2001, What have we learned from a decade of empirical research on growth? It's not Factor accumulation: stylized facts and growth models, The World Bank Economic Review 15, 177-219.

Eaton, J. and S. Kortum, 1999, International patenting and technology diffusion: Theory and measurement, International Economic Review 40, 537-70.

Eurostat (2012), Educational expenditure statistics (http://epp.eurostat.ec.europa.eu/statistics_explained/index.p

Fogli, A. and L. Veldkamp, 2011, Germs, social networks and growth, mimeo, University of Minnesota. 
Galor, O., 2005, From stagnation to growth: unified growth theory, in: P. Aghion and S. Durlauf, Handbook of Economic Growth Vol 1A, Amsterdam, North-Holland.

Galor, O. and Weil, D.N., 2000, Population,technology and growth: From the Malthusian regime to the demographic transition and beyond, American Economic Review 110, 806-828.

Galor, O. and Moav, O., 2002, Natural selection and the origin of economic growth, Quarterly Journal of Economics 117, 1133-1192.

Galor, O. and Moav, O., 2004, From physical to human capital accumulation: Inequality and the process of development, Review of Economic Studies 71, 1001-1026.

Galor, O. and A. Mountford, 2008, Trading population for productivity: theory and evidence, Review of Economic Studies 75, 1143-1179.

Gerschenkron, A., 1962, Economic backwardness in historical perspective, in: Hoselitz, B. (ed.) The Progress of Underdeveloped Areas, Chicago University Press, Chicago.

Howitt, P., 2000, Endogenous growth and cross-country income differences, American Economic Review 90, 829-846.

Jackson, M.O. and L. Yariv (2007), Diffusion of Behavior and Equilibrium Properties in Network Games, American Economic Review (Papers and Proceedings), 97(2), 92-98.

Jones, C. I., 1997, On the evolution of the world income distribution, Journal of Economic Perspectives 11(3), 19-36.

Jones, C.I., 2001, Was an industrial revolution inevitable? Economic growth over the very long run, Advances in Macroeconomics 1, 1-43.

Jones, C.I. and Romer, P.M., 2010, The new Kaldor facts: ideas, institutions, population, and human capital, American Economic Journal: Macroeconomics 2, 224-245.

Kaldor, N., 1961, Capital accumulation and economic growth, in: The Theory of Capital, ed. F.A. Lutz and D.C. Hague, St. Martins Press, New York.

Keller, W., 2002, Geographic localization of international technology diffusion, American Economic Review 92, 120-142.

Klenow, P.J. and Rodriguez-Clare, A., 2005, Externalities and growth, in: Aghion, P. and S.N. Durlauf (eds.) Handbook of Economic Growth Vol. 1, 817-861, Elsevier, Amsterdam.

Kuznets, S., 1966, Modern Economic Growth: Rate, Structure and Spread, Yale University Press, New Haven.

Lindner, I. and Strulik, H., 2012, From Tradition to Modernity: Economic Growth in a Small World, Discussion Paper, University of Hannover.

Lucas, R.E., 2000, Some Macroeconomics for the 21st century, Journal of Economic Perspectives 14, 159-168.

Lucas, R.E., 2009, Trade and the industrial revolution, American Economic Journal: Macroe- 
conomics 1, 1-25.

Newman, M.E.J., 2003, The structure and function of complex networks, SIAM Review 45, 167-256.

Parente, S.L. and Prescott, E.D., 1994, Barriers to technology adoption and development, Journal of Political Economy 102, 298-32.

Parente, S.L. and Prescott, E.D., 2005, A unified theory of the evolution of international income levels, in: Aghion, P. and S.N. Durlauf (eds.) Handbook of Economic Growth, Elsevier, Amsterdam, Chapter 21.

Pomeranz, K., 2000, The Great Divergence: China, Europe, and the Making of the Modern World, Princeton, Princeton University Press.

Romer, P.M., 1986, Increasing returns and long-run growth, Journal of Political Economy 94, 1002-1037.

Sala-i-Martin, X., 2006, The world distribution of income: falling poverty and convergence, period Quarterly Journal of Economics 121, 351-397.

336-352.

Strulik, H., 2009, Knowledge and growth in the very long run, International Economic Review, Discussion Paper, University of Hannover.

Strulik, H. and Weisdorf, J., 2008, Population, food, and knowledge: A simple unified growth model, Journal of Economic Growth 13, 169-194.

Strulik, H., Prettner, K., and Prskwetz, A., 2013, The past and future of knowledge-based growth, Journal of Economic Growth, 18, 411-437.

Sutcliffe, B., 2004, World inequality and globalization, Oxford Review of Economic Policy 20, $15-37$.

Ventura, J., 2005, A global view of economic growth, in: P. Aghion and S. Durlauf, Handbook of Economic Growth Vol 1B, Amsterdam, North-Holland.

Watts, D.J., and S.H. Strogatz, 1998, Collective dynamics of 'small-world" networks, Nature $393,440-442$. 


\section{APPENDIX}

Matrix Notation. Bridge network, $n=7,3$ initially rich.

$$
\overline{\mathbf{W}}=\left(\begin{array}{ccccccc}
\frac{1}{2} & \frac{1}{6} & \frac{1}{6} & 0 & 0 & 0 & \frac{1}{6} \\
\frac{1}{4} & \frac{1}{2} & \frac{1}{4} & 0 & 0 & 0 & 0 \\
\frac{1}{4} & \frac{1}{4} & \frac{1}{2} & 0 & 0 & 0 & 0 \\
0 & 0 & 0 & \frac{1}{2} & \frac{1}{6} & \frac{1}{6} & \frac{1}{6} \\
0 & 0 & 0 & \frac{1}{6} & \frac{1}{2} & \frac{1}{6} & \frac{1}{6} \\
0 & 0 & 0 & \frac{1}{6} & \frac{1}{6} & \frac{1}{2} & \frac{1}{6} \\
\frac{1}{8} & 0 & 0 & \frac{1}{8} & \frac{1}{8} & \frac{1}{8} & \frac{1}{2}
\end{array}\right) \quad \mathbf{H}(\mathbf{0})=\left(\begin{array}{c}
1.2 \\
1.2 \\
1.2 \\
1.0 \\
1.0 \\
1.0 \\
1.0
\end{array}\right) \quad \overline{\mathbf{W}} \mathbf{H}(\mathbf{0})=\left(\begin{array}{c}
1.17 \\
1.2 \\
1.2 \\
1.0 \\
1.0 \\
1.0 \\
1.02
\end{array}\right)
$$

Ring network, $m=1, n=9,3$ initially rich.

$$
\overline{\mathbf{W}}=\left(\begin{array}{ccccccccc}
\frac{1}{2} & \frac{1}{4} & 0 & 0 & 0 & 0 & 0 & 0 & \frac{1}{4} \\
\frac{1}{4} & \frac{1}{2} & \frac{1}{4} & 0 & 0 & 0 & 0 & 0 & 0 \\
0 & \frac{1}{4} & \frac{1}{2} & \frac{1}{4} & 0 & 0 & 0 & 0 & 0 \\
0 & 0 & \frac{1}{4} & \frac{1}{2} & \frac{1}{4} & 0 & 0 & 0 & 0 \\
0 & 0 & 0 & \frac{1}{4} & \frac{1}{2} & \frac{1}{4} & 0 & 0 & 0 \\
0 & 0 & 0 & 0 & \frac{1}{4} & \frac{1}{2} & \frac{1}{4} & 0 & 0 \\
0 & 0 & 0 & 0 & 0 & \frac{1}{4} & \frac{1}{2} & \frac{1}{4} & 0 \\
0 & 0 & 0 & 0 & 0 & 0 & \frac{1}{4} & \frac{1}{2} & \frac{1}{4} \\
\frac{1}{4} & 0 & 0 & 0 & 0 & 0 & 0 & \frac{1}{4} & \frac{1}{2}
\end{array}\right) \quad \mathbf{H}(\mathbf{0})=\left(\begin{array}{c}
1.2 \\
1.2 \\
1.2 \\
1.0 \\
1.0 \\
1.0 \\
1.0 \\
1.0 \\
1.0
\end{array}\right) \quad \overline{\mathbf{W}} \mathbf{H}(\mathbf{0})=\left(\begin{array}{c}
1.15 \\
1.2 \\
1.15 \\
1.05 \\
1.0 \\
1.0 \\
1.0 \\
1.0 \\
1.05
\end{array}\right)
$$

Core-periphery, $n=13,4$ initially rich (4 peripheries).

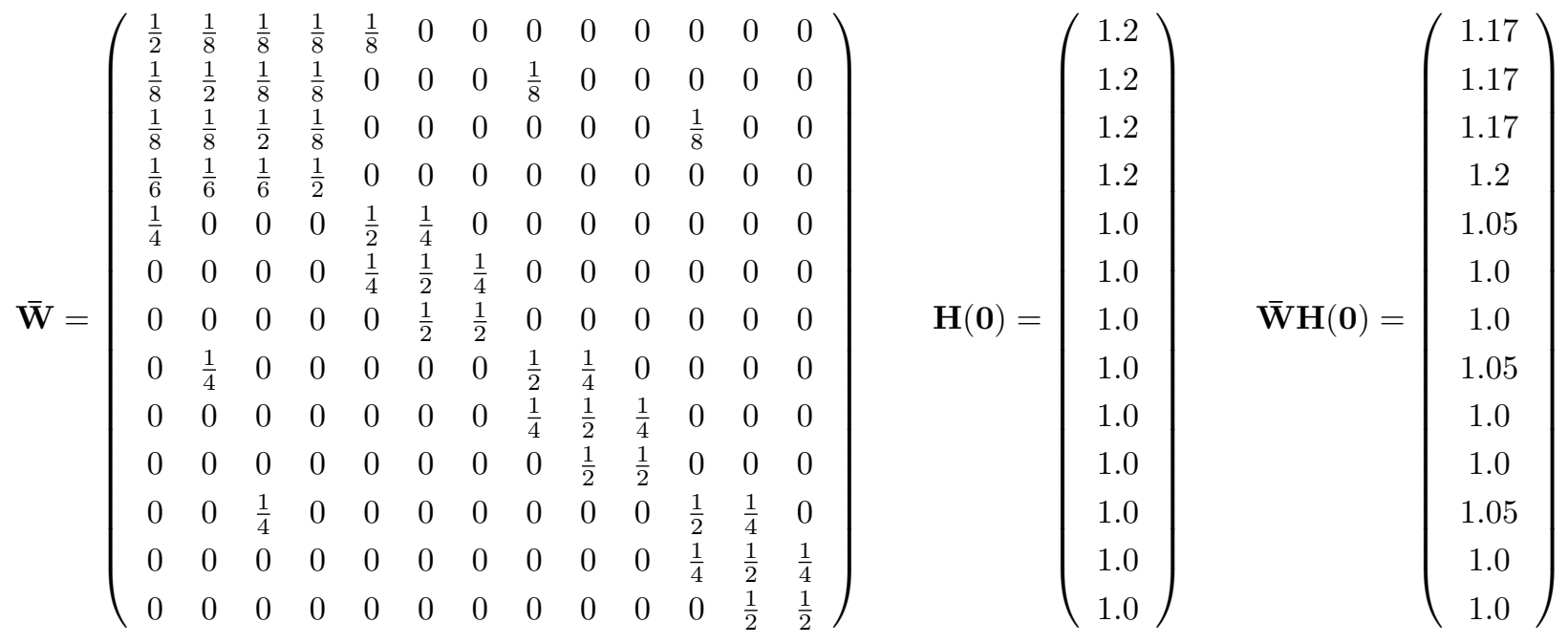

\section{Proof of Proposition 1.}

Proof. Assume the society starts in $h_{0}=\left(h_{10}, \ldots, h_{n 0}\right)$. Put $h_{\max 0}=\max \left\{h_{10}, \ldots, h_{n 0}\right\}$.. Let $i$ denote the country with $h_{i 0}=h_{\max 0}$. Since $A_{i t}$ takes weighted averages of human capital we get as an upper bound $A_{i \max 0} \leq h_{i \max 0}$. Growth of country-specific human capital is therefore bounded from above by the scenario where $i$ is linked exclusively to a country $j \neq i$ that belongs 
to the richest group at the beginning and there are no other links between $i$ and $j$. In this case we get $A_{i t}=h_{j t}=h_{i t}$ and (8) simplifies to $h_{i, t+1}=\max \left\{1, L \cdot\left(h_{i t}-\bar{c}\right)^{\eta}\right\}$. The scalar function $f(h)=L \cdot(h-\bar{c})^{\eta}$ is concave for $\eta<1$ and depending on parameter values has two or less intersection points with the identity line.

Case 1: Two intersection points with the identity line. In this case the larger fix point of the equation $h^{*}=f\left(h^{*}\right)$ is stable.

Case 2: Less than two intersection points. Here, $f(h)$ is either equal or below the identity line for all $h$. Hence $h_{i \max , t+1} \leq \max \left\{1, L \cdot\left(h_{i \max 0}-\bar{c}\right)^{\eta}\right\}$ for all $t \geq 0$ such that growth eventually declines.

For $\eta=1, L \leq 1$ ensures that $h_{i \max , t+1}=\max \left\{1, L \cdot\left(h_{i \max t}-\bar{c}\right)\right\} \leq \max \left\{1, h_{i \max 0}\right\}$, which verifies the absence of long-run growth.

\section{Proof of Proposition 2.}

Proof. With identical human capital endowments the neighborhood weighted average of human capital is given by $A_{i t}=h_{i t}$. Equation (6) simplifies to

$$
g_{i t}^{h} \equiv \frac{h_{i, t+1}}{h_{i t}}=\max \left\{\frac{1}{h_{i t}}, L \cdot \frac{\left(h_{i t}-\bar{c}\right)^{\eta}}{h_{i t}}\right\}
$$

which provides equal growth rates for equal levels of human capital.

\section{Proof of Proposition 3.}

Proof. We discuss the case $\eta<1$ first. Proposition 1 states convergence to an equilibrium for all countries. Assume that there is an asymmetric stable equilibrium $h^{*}=\left(h_{1}^{*}, \ldots, h_{n}^{*}\right)$ and put $h_{\max }^{*}=\max \left\{h_{1}^{*}, \ldots, h_{n}^{*}\right\}$. Since the network is connected there exists a country $r$ with $h_{r}^{*}=h_{\max }^{*}$ but lower average human capital of its neighborhood $\bar{h}_{r}^{*}<h_{\max }^{*}$. We will show below that the function

$$
f(h)=L \cdot\left([\epsilon \bar{h}+(1-\epsilon) h]^{1-\alpha} h^{\alpha}-\bar{c}\right)^{\eta}
$$

derived from (8) is concave in $h$ for $\eta<1$. Note that (A.1) is the same for all countries aside from the neighborhood average $\bar{h}$. Since $f(h)$ is concave the stable equilibrium is the upper intersection of $f(h)$ with the identity line. The upper intersection increases with $\bar{h}$. The country with the highest intersection $h_{\max }^{*}$ is therefore a country with maximal neighborhood average $\bar{h}_{\text {max }}$ which contradicts our construction of $r$. We conclude that there are no stable asymmetric equilibria which also rules out unstable asymmetric equilibria (lower intersection of (A.1)).

It remains to be shown that $f(h)$ in (A.1) is concave. Put $f(h)=z(g(h))$, with $g(h)=$ $[\varepsilon \bar{h}+(1-\varepsilon) h]^{1-\alpha} h^{\alpha}-\bar{c}$ and $z(y)=L y^{\eta}$. For the second derivative of $f$ follows

$$
f^{\prime \prime}(h)=z^{\prime \prime}(g(h))(g(h))^{2}+z^{\prime}(g(h)) g^{\prime \prime}(h) .
$$

For $\eta<1$ we have $z^{\prime \prime}(g(h))<0$ such that the left term in the sum of (A.2) is negative. A sufficient condition for $f^{\prime \prime}(h)<0$ is therefore that $g^{\prime \prime}(h)<0$ since $z^{\prime}(h)>0$. Put

$$
g(h)=u(h) v(h) \text { with } u(h)=[\varepsilon \bar{h}+(1-\varepsilon) h]^{1-\alpha} \text { and } v(h)=h^{\alpha} .
$$

The second derivative of $g$ is $g^{\prime \prime}=u^{\prime \prime} v+2 u^{\prime} v^{\prime}+u v^{\prime \prime}$ and after dividing $g^{\prime \prime}(h)<0$ by $u^{\prime} v^{\prime}$ we 
get

$$
\frac{u^{\prime \prime}}{u^{\prime}} \frac{v}{v^{\prime}}+2+\frac{u}{u^{\prime}} \frac{v^{\prime \prime}}{v^{\prime}}<0
$$

The fractions in this inequality are given by

$$
\begin{aligned}
\frac{u^{\prime \prime}}{u^{\prime}}=-\frac{\alpha(1-\varepsilon)}{\varepsilon \bar{h}+(1-\varepsilon) h}, & \frac{v}{v^{\prime}}=\frac{h}{\alpha}, \\
\frac{u}{u^{\prime}}=\frac{\varepsilon \bar{h}+(1-\varepsilon) h}{(1-\alpha) b}, & \frac{v^{\prime \prime}}{v^{\prime}}=-\frac{(1-\alpha)}{h} .
\end{aligned}
$$

Inserting (A.4) into (A.3) gives

$$
-(1-\varepsilon) \frac{h}{\varepsilon \bar{h}+(1-\varepsilon) h}+2-\frac{1}{(1-\varepsilon)} \frac{\varepsilon \bar{h}+(1-\varepsilon) h}{h}<0 .
$$

Multiplying (A.5) by

$$
-\frac{1}{(1-\varepsilon)} \frac{h}{\varepsilon \bar{h}+(1-\varepsilon) h}
$$

provides

$$
\left(\frac{h}{\varepsilon \bar{h}+(1-\varepsilon) h}\right)^{2}-2 \frac{h}{\varepsilon \bar{h}+(1-\varepsilon) h} \frac{1}{(1-\varepsilon)}+\left(\frac{1}{(1-\varepsilon)}\right)^{2}>0
$$

which simplifies to

$$
\left(\frac{h}{\varepsilon \bar{h}+(1-\varepsilon) h}-\frac{1}{(1-\varepsilon)}\right)^{2}>0
$$

which always holds unless $\bar{h}=0$.

Finally consider the case $\eta=1$. The term $z^{\prime \prime}(g(h)$ in (A.2) equals zero such that a sufficient condition for $f^{\prime \prime}(h)<0$ is $g^{\prime \prime}(h)<0$, which is analogous to the case $\eta<1$. Analogously, we can rule out asymmetric equilibria for $\eta=1$. For $\bar{h}=h$ and $\eta=1$ the function $f(h)$ in (A.1) is linear and lies below the identity line $f(h)=h$ without intersection, a fact that implies convergence to subsistence.

Proof of Proposition 4. For $\eta=1$ the growth rate of country $i$ after the take-off is given by

$$
\begin{aligned}
h_{i t+1} / h_{i t} & =L\left(\left[\epsilon \bar{h}_{i t}+(1-\epsilon) h_{i t}\right]^{1-\alpha} h_{i t}^{\alpha}-\bar{c}\right) / h_{i t}=L\left(\left[\epsilon \frac{\bar{h}_{i t}}{h_{i t}}+(1-\epsilon)\right] h_{i t}-\bar{c}\right) / h_{i t} \\
& =L\left[\epsilon \frac{\bar{h}_{i t}}{h_{i t}}+(1-\epsilon)\right]-L \frac{\bar{c}}{h_{i t}} .
\end{aligned}
$$

As we will show in Proposition 7 the relative distance between countries in connected components tends to zero. This is equivalent to $\bar{h}_{i t} / h_{i t}$ tending to one, either because both $\bar{h}_{i t}$ and $h_{i t}$ stagnate or because both grow forever. The implied growth rate in the latter case is $h_{i t+1} / h_{i t}=L[\epsilon \cdot 1+(1-\epsilon)]-L \cdot 0=L$.

Proof of Proposition 5. Jackson and Yariv (2007) use a similar argument to prove S-shaped rates of adoption (see their Proposition 7).

Put $u(\xi)=[\epsilon \xi+(1-\epsilon)]^{1-\alpha}$ such that $g(\xi(h), h)=u(\xi(h))-\bar{c} / h$. Notice that the conditions of the propositions imply $\xi^{\prime \prime}(h)<0$ and that $\xi^{\prime}(h)$ changes from positive to negative. For the 
derivatives follows

$$
\begin{aligned}
\frac{d}{d h} g(\xi(h), h) & =u^{\prime}(\xi) \xi^{\prime}(h)+\frac{\bar{c}}{h^{2}}=\epsilon(1-\alpha)[\epsilon \xi+(1-\epsilon)]^{-\alpha} \xi^{\prime}(h)+\frac{\bar{c}}{h^{2}}>0 \\
\frac{d^{2}}{(d h)^{2}} g(h) & =\underbrace{\epsilon^{2}(1-\alpha)(-\alpha)[\epsilon \xi+(1-\epsilon)]^{-\alpha-1}\left[\xi^{\prime}(h)\right]^{2}}_{<0}+\underbrace{\epsilon(1-\alpha)[\epsilon \xi+(1-\epsilon)]^{-\alpha} \xi^{\prime \prime}(h)}_{<0 \text { since } \xi^{\prime \prime}<0} \underbrace{-2 \frac{\bar{c}}{h^{3}}}_{<0} .
\end{aligned}
$$

Put $f(h)=[\epsilon \xi(h)+(1-\epsilon)]^{1-\alpha} h-\bar{c}=u(\xi(h)) h-\bar{c}$. We get

$$
\begin{aligned}
u^{\prime}(\xi) & =\underbrace{(1-\alpha) \epsilon[\epsilon \xi+(1-\epsilon)]^{-\alpha}}_{>0}=\frac{(1-\alpha) \epsilon}{\epsilon \xi+(1-\epsilon)} u(\xi)<u(\xi) \text { if } \xi \geq 1 . \\
f^{\prime}(h) & =\underbrace{u^{\prime}(\xi) \xi^{\prime}(h) h}_{\text {positive first, then negative }}+u(\xi(h)) \\
& =\frac{(1-\alpha) \epsilon}{\epsilon \xi+(1-\epsilon)} u(\xi) \xi^{\prime}(h) h+u(\xi)=\left[\frac{(1-\alpha) \epsilon}{\epsilon \xi+(1-\epsilon)} \xi^{\prime}(h) h+1\right] u(\xi) \\
f^{\prime \prime}(h) & =u^{\prime \prime}(\xi)\left(\xi^{\prime}(h)\right)^{2} h+u^{\prime}(\xi)\left[\xi^{\prime \prime}(h) h+\xi^{\prime}(h)\right]+u^{\prime}(\xi) \xi^{\prime}(h) \\
& =\underbrace{u^{\prime \prime}(\xi)\left(\xi^{\prime}(h)\right)^{2} h}_{<0}+u^{\prime}(\xi) \quad \underbrace{\left[\xi^{\prime \prime}(h) h+2 \xi^{\prime}(h)\right]}_{<0 \text { if } \xi^{\prime \prime}(h)<0 \text { and } \xi^{\prime}(h) \text { approaches } 0 \text { or gets negative. }}
\end{aligned}
$$

Now put $y=f(h)$. Since $h$ is increasing we have $y>h$. We know that for $\xi^{\prime}>0$ it follows that $g^{\prime}(y)$ and $g^{\prime}(h)$ are positive. Since $g^{\prime \prime}(h)<0$ it holds that $g^{\prime}(y)>g^{\prime}(h)$. We get $(g(y)-g(h))^{\prime}=g^{\prime}(y) f^{\prime}(h)-g^{\prime}(h)$ and $(g(y)-g(h))^{\prime}>0$ is equivalent to

$$
f^{\prime}(h)>\frac{g^{\prime}(h)}{g^{\prime}(y)} .
$$

Note that eventually $f^{\prime \prime}(h)<0$.

We distinguish 3 cases:

(1) $f^{\prime}(h)$ is larger than $g^{\prime}(h) / g^{\prime}(y)$ initially and equal to $g^{\prime}(h) / g^{\prime}(y)$ for finite $\hat{h}>1$, i.e. finite time $T>0$. This implies that the growth rate reaches a maximum $T$ and decreases afterwards. There is overshooting growth.

(2) $f^{\prime}(h)$ is always smaller than $g^{\prime}(h) / g^{\prime}(y)$. In that case $T=0$ and the growth rate keeps decelerating during the whole process.

(3) $f^{\prime}(h)$ is larger than $g^{\prime}(h) / g^{\prime}(y)$ but does not pass it in finite time such that $T=\infty$. This means that there is long run growth but no overshooting growth.

Proof of Proposition 6. We define as overshooting the temporary surpassing of the long run growth rate (global overshooting). In case of positive long-run growth the long-run growth rate is given by $L$. Thus, country $i$ overshoots at time $t$ if $g_{i t}^{h}>L$. We next show that overshooting occurs due to a sufficiently high lag of human capital with respect to the neighborhood average. For $\eta=1$ we have $g_{i t}^{h}>L$ iff 


$$
\left[\epsilon \frac{\bar{h}_{i t}}{h_{i t}}+(1-\epsilon)\right]^{1-\alpha}=\left[1+\epsilon\left(\frac{\bar{h}_{i t}}{h_{i t}}-1\right)\right]^{1-\alpha}>1+\frac{\bar{c}}{h_{i t}} .
$$

We first prove that the richest country can never overshoot. The second step provides a sufficient condition for overshooting.

(i) Put $m_{t}=\arg \max _{i} h_{i t}$. It follows that growth at time $t$ is bounded from above by a growth scenario in which country $m$ is exclusively linked with an identical twin and vice versa. For $g_{m t}^{h}$ we get

$$
g_{m t}^{h} \leq \frac{L \cdot\left(\left[\epsilon h_{m t}+(1-\epsilon) h_{m t}\right]^{1-\alpha} h_{m t}^{\alpha}-\bar{c}\right)}{h_{m t}}=\frac{L \cdot\left(h_{m t}-\bar{c}\right)}{h_{m t}} \leq L .
$$

(ii) The growth rate is given by $g(h)=L \cdot\left([\epsilon \bar{h}+(1-\epsilon) h]^{1-\alpha} h^{\alpha}-\bar{c}\right) / h$.

From Proposition 3 we know that the long run growth rate is $L$. Overshooting means that at some point $g(h)>L$, i.e.

$$
\left[\epsilon \frac{\bar{h}}{h}+(1-\epsilon)\right]^{1-\alpha}-\frac{\bar{c}}{h}>1 \Leftrightarrow\left[\epsilon \frac{\bar{h}}{h}+(1-\epsilon)\right]^{1-\alpha}>1+\frac{\bar{c}}{h} .
$$

Note that for $\epsilon=0$ the left hand side simplifies to 1 and hence the inequality is never fulfilled which confirms that global overshooting is triggered by sufficiently large $\bar{h} / h$. In particular, overshooting occurs if

$$
\begin{gathered}
\epsilon \frac{\bar{h}}{h}+(1-\epsilon)>\left(1+\frac{\bar{c}}{h}\right)^{\frac{1}{1-\alpha}} \Leftrightarrow \frac{\bar{h}}{h}>\frac{1}{\epsilon}\left(1+\frac{\bar{c}}{h}\right)^{\frac{1}{1-\alpha}}-\frac{1-\epsilon}{\epsilon}>1 \\
\Leftrightarrow \frac{\bar{h}}{h}>1+\frac{1}{\epsilon}\left[\left(1+\frac{\bar{c}}{h}\right)^{\frac{1}{1-\alpha}}-1\right] .
\end{gathered}
$$

Proof of Proposition 7. Put $H=\sum_{i=1}^{n} h_{i}$. Define distance $d$ and normalized distance $\hat{d}$ as $d=\max _{i, j}\left|h_{i t}-h_{j t}\right|$ and $\hat{d}=d / H$.

LEMma 1. The Gini coefficient tends to zero if and only if normalized difference tends to zero.

Proof. The Gini coefficient is defined by means of the the area under the Lorenz curve. Without loss of generality assume the countries are labeled such that $h_{1} \leq h_{2} \leq \ldots \leq h_{n}$. Put $H_{k}=$ $\operatorname{sum}_{i=1}^{k} h_{i}$. The Lorenz curve is a polygonial line defined by the set of points

$$
\left\{(0,0),\left(\frac{1}{n}, \frac{H_{1}}{H}\right),\left(\frac{2}{n}, \frac{H_{2}}{H}\right), \ldots,\left(\frac{n-1}{n}, \frac{H_{n-1}}{H}\right),(1,1)\right\} .
$$

The Gini coefficient is zero if and only the Lorenz curve is the identity line, which means, in particular, that the first slope of the polygonal line $n h_{1} / H$ and the slope of the last polygonial line $n h_{n} / H$ are identical. We conclude that the Gini coefficient converges to zero if and only if

$$
n \hat{d}=n\left(\frac{h_{n}}{H}-\frac{h_{1}}{H}\right) \rightarrow 0 .
$$


We will now turn to the question under what conditions the Gini coefficient tends to zero. From Proposition 1 we know that for $\eta<1$ long run growth is not possible and all countries eventually converge to the same human capital level if the network connected. This implies that for $\eta<1$ the Gini coefficient always tends to zero if there is a path between any two countries.

For $\eta=1$ we first show that the dynamics

$$
h_{i t+1}=L \cdot \max \left\{1, u\left(h_{i t}, \bar{h}_{i t}\right)\right\}
$$

with

$$
u\left(h_{i t}, \bar{h}_{i t}\right)=\left[\epsilon \bar{h}_{i t}+(1-\epsilon) h_{i t}\right]^{1-\alpha} h_{i t}^{\alpha}-\bar{c}
$$

consists of 2 subsequent steps: (i) $u$ is a contraction mapping which decreases distance and (ii) scaling, i.e. multiplication by $L$.

Lemma 2. Let the network be connected. For $\eta=1$ and $L \leq 1$ distance $d_{t}$ decreases monotonically to zero after the last take-off. For $L \geq 1$ distance $d_{t}$ grows slower than $L^{t}$, in short,

$$
d_{t}=o\left(L^{t}\right) .
$$

Proof. Put $h_{r t}=\max _{i} h_{i t}, h_{p t}=\min _{i} h_{i t}$. For the largest difference follows

$d_{t+1} \leq L\left[\epsilon h_{r t}+(1-\epsilon) h_{r t}\right]^{1-\alpha} h_{r t}^{\alpha}-L\left[\epsilon h_{p t}+(1-\epsilon) h_{p t}\right]^{1-\alpha} h_{p t}^{\alpha} \leq L h_{r t}-L h_{p t} \leq d_{t}$ for $L \leq 1$.

Let $S_{r t}=\left\{i \in N \mid h_{i t}=\max _{j \in N} h_{j t}\right\}$ denote the set of countries with the highest human capital level at time $t$. From time $t$ to $t+1$ it is possible that countries leave or join this set due to externality effects. However, since the network is connected it is not possible that countries in $S_{r t} \neq N$ develop forever with an externality level $\bar{h}_{r t}=h_{r t}$. At some point in time the richest countries face an externality level $\bar{h}_{r t}<h_{r t}$ such that $h_{r t+1}<h_{r t}$. Analogously, since the poorest countries are not isolated we have $h_{p t+1}>h_{p t}$ at some point in time such that $d_{t+1}<d_{t}$.

Finally, we conclude that the mapping $u$ from (A.7) never increases distance and that there exists a $t>0$ such that $u$ is a contraction. This contraction is followed by multiplication with $L$ in (A.6). This implies that $d_{t}$ has the shape of $L^{t}$ multiplied by a zero sequence, in short, $d_{t}$ grows slower than $L^{t}$, as displayed in (A.8).

\section{LEMma 3. The Gini coefficient tends to zero in connected networks.}

Proof. From Lemma 2 we know that all $h_{i t}$ values lie in an interval $I_{t}$ with measure $\mu\left(I_{t}\right)=o\left(L^{t}\right)$. In other words, there exists a $h^{*}$ s such that $h_{i t} / L^{t} \rightarrow h^{*}$ for any $i \in N$. In conclusion we get for $H_{t}=\sum_{i=1}^{n} h_{i t}$ that $H_{t} / L^{t} \rightarrow n h^{*}$. For the normalized difference we get

$$
\hat{d}_{t}=\frac{d_{t}}{H_{t}}=\frac{d_{t} / L^{t}}{H_{t} / L^{t}} \rightarrow \frac{0}{n h^{*}}=0 .
$$

From Lemma 2 we conclude that the Gini coefficient tends to zero. 
Proof of Proposition 8. The proposition is proven by way of example. Consider the bridge network from Figure 3 with $n=10$ and half of the population starts rich. All other settings are as in the benchmark case, in particular $\eta=1$ and $L=1.48>1$ ensure long run growth. Figure A.1 illustrates the time path of the largest human capital difference $d_{t}$ with an example. The largest difference grows exponentially, which can be explained by inspecting

$$
\begin{aligned}
f(h) & =L \cdot\left([\epsilon \bar{h}+(1-\epsilon) h]^{1-\alpha} h^{\alpha}-\bar{c}\right)=L \cdot\left(\left[\epsilon \frac{\bar{h}}{h}+(1-\epsilon)\right] h-\bar{c}\right) \\
& =L \cdot\left(\left[\epsilon \frac{\bar{h}}{h}+(1-\epsilon)\right]-\bar{c} / h\right) h \approx L \cdot\left[\epsilon \frac{\bar{h}}{h}+(1-\epsilon)\right] h
\end{aligned}
$$

for large $h$. The dense connectedness of neighbors with similar endowments of human capital implies that $h$ essentially grows each time by a factor $L$ which explains why the shape of $d_{t}$ behaves similar to $L^{t} d_{1}$. Given the explosive growth of largest distance it might seem puzzling that the Gini coefficient declines. For that recall that the Gini coefficient works with a normalization. It uses relative instead of absolute numbers.

Figure A.1: Largest Difference of Human Capital Levels. Bridge Network

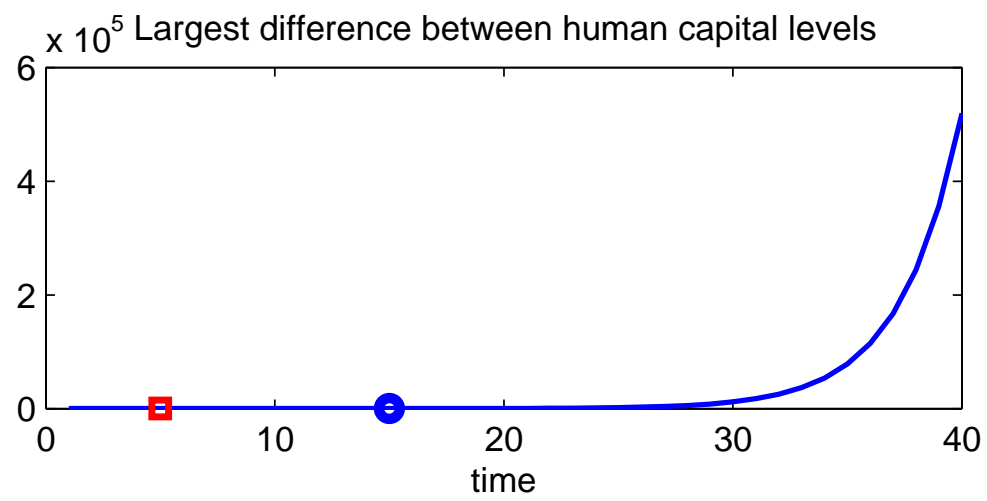

Time measured in generations. The red square indicates the time of the last take off to growth; the blue circle indicates the time when the Gini coefficient assumes its maximum.

Decreasing and Increasing Returns. Consider a generalization of the model in which $A_{i t}=$ $\left(\sum_{j=1}^{n} \bar{w}_{i j} h_{j t}\right)^{\omega}, \omega \neq 1-\alpha$, replaces (7). Aggregate production displays decreasing returns to scale for $\omega<(1-\alpha)$ and increasing returns to scale for $\omega>(1-\alpha)$. The latter case is interesting because it allows for positive growth at the steady-state without the need of linear returns to education (without the need of $\eta=1$ ). Figure A.2 shows such a case in which a high value for the importance of international knowledge flows $\omega$ compensates for decreasing returns in education $(\epsilon=0.75)$. Nevertheless there is long-run growth. The value of $B$ has been adjusted in order to arrive at a steady-state growth rate of 1.5 percent. To the naked eye the figure looks very similar to Figure 6 in the paper.

The case of decreasing returns to scale is interesting to investigate dynamics when there is no positive growth at the steady state. Figure A.3 shows the result for an example in which there are mildly decreasing returns to scale $(\omega=0.45)$ as well as mildly decreasing returns to education 
Figure A.2: Decreasing Returns to Education and Steady Growth

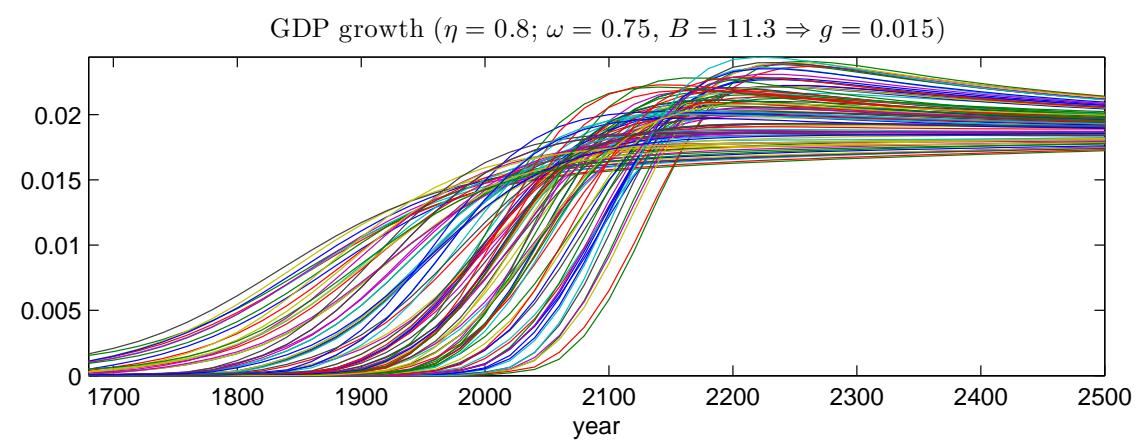

$(\eta=0.95)$. It demonstrates that historically plausible growth trajectories can obtained without relying on positive exponential growth at the steady-state.

Figure A.3: Decreasing Returns to Education and Decreasing Returns to Scale

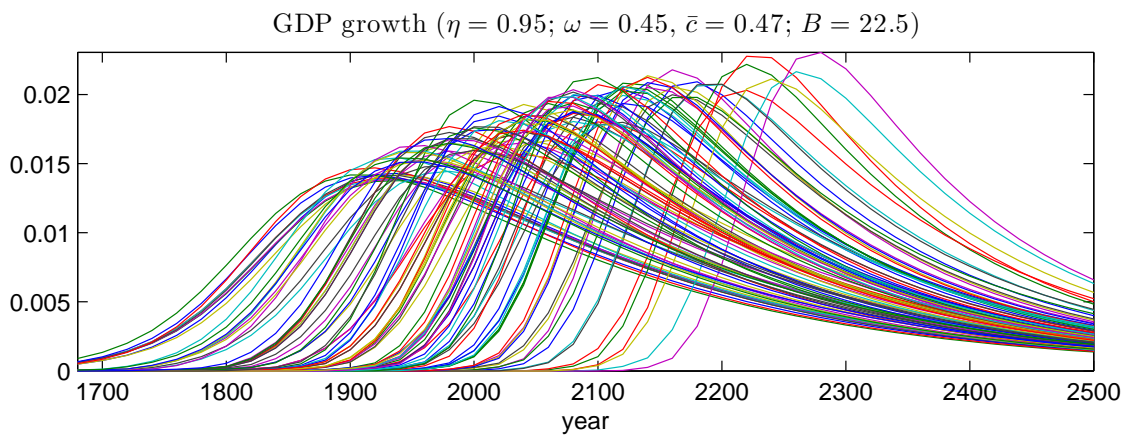

Just England. It could be argued that initially there was just one forerunner of the industrial revolution, England. From there the take off to growth spread across the world. To cover this case we assume that initially there is only 1 rich country and 99 poor countries. All other parameters are kept from the benchmark model. Recall that in the benchmark case $\bar{c}=0.33$ such that industrialization is possible (but not inevitable) when there is just one initially growing country. Figure A.4 shows the growth trajectories for such an example. Compared to the benchmark case it takes much longer until the industrial revolution diffuses around the world but otherwise the evolution of world income is structurally similar. 
Figure A.4: Just England

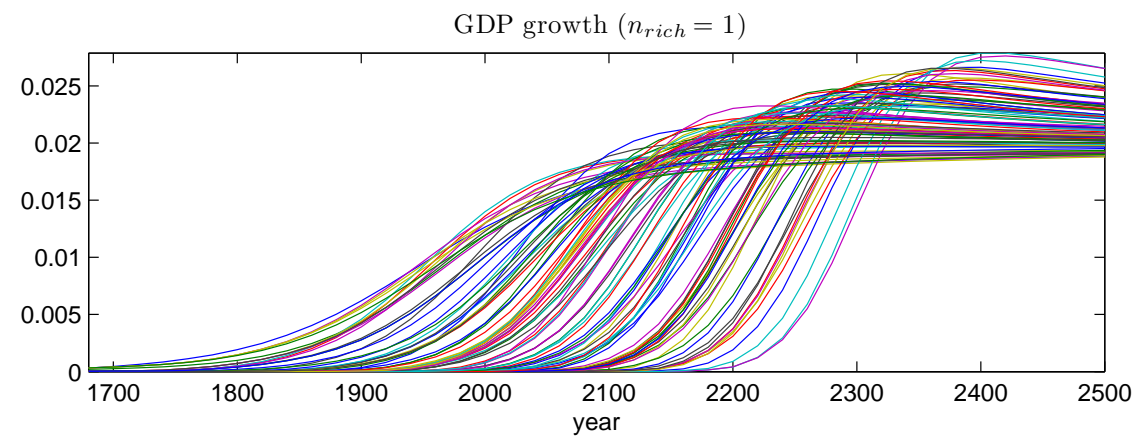

